CUADERNOS DE ESTUDIOS GALLEGOS, LX Núm. 126 (enero-diciembre 2013), págs. 85-123

ISSN: 0210-847 X

DOI: 10.3989/ceg.2013.126.03

\title{
CARTAS DE FUERO Y LICENCIAS $A D$ POPULANDUM DEL MONASTERIO DE LORENZANA. CONTRIBUCIÓN AL CORPUS DE LOS FUEROS RURALES DE GALICIA
}

José A. Álvarez CASTrillón

Universidad de Oviedo 


\title{
CARTAS DE FUERO Y LICENCIAS AD POPULANDUM DEL MONASTERIO DE LORENZANA. CONTRIBUCIÓN AL CORPUS DE LOS FUEROS RURALES DE GALICIA
}

\section{RESUMEN}

El conocimiento del intenso proceso de reorganización social y económica que desde mediados del siglo XIII se produce en la marina oriental gallega, y que en esencia ha fijado el paisaje posterior, ha tenido habitualmente como paradigma y referente el abundante conjunto de cartas de fuero del monasterio cisterciense de Santa María de Meira. No obstante, y acaso en parte como consecuencia de la azarosa trayectoria de sus fondos, ha pasado casi desapercibido el importante conjunto documental homólogo del monasterio benedictino de San Salvador de Vilanova de Lorenzana, en buena medida réplica al anterior, y sin duda el contrapunto perfecto para un análisis coherente del proceso. Las referencias conocidas, además de su hasta ahora inevitable carácter fragmentario, adolecen con frecuencia de defectos de transcripción y data que desvirtúan su utilidad testimonial. El trabajo, resultado de una dilatada labor heurística en diversos fondos, ha permitido sumar tres piezas a la docena conservada bajo la signatura de Lorenzana del AHN, y ofrece la transcripción de 15 documentos, 10 de ellos inéditos, reuniendo el importante y elocuente conjunto de cartas de fuero y licencias de población con que el monasterio documentó su política repobladora. Se acompaña de una aproximación tipológica.

PALABRAS ClAVE: Fueros, licencias de población, monasterio, Lorenzana.

\section{CARTAS DE FORO E LICENCIAS AD POPULANDUM DO MOSTEIRO DE LOURENZÁ. CONTRIBUCIÓN Ó CORPUS DOS FOROS RURAIS DE GALICIA}

\section{RESUMo}

O coñecemento do intenso proceso de reorganización social e económica que dende mediados do século XIII se produce na mariña oriental galega, e que en esencia fixou a paisaxe posterior, tivo habitualmente como paradigma e referente o abundante conxunto de cartas de foro do mosteiro cisterciense de Santa María de Meira. Non obstante, e acaso en parte como consecuencia da azarosa traxectoria dos seus fondos, pasou case desapercibido o importante conxunto documental homólogo do mosteiro beneditino de San Salvador de Vilanova de Lourenzá, en boa medida réplica ao anterior, e sen dúbida o contrapunto perfecto para unha análise coherente do proceso. As referencias coñecidas, ademais do seu ata agora inevitable carácter fragmentario, adoecen con frecuencia de defectos de transcrición e data que desvirtúan a súa utilidade testemuñal. O traballo, resultado dun dilatado labor heurístico en diversos fondos, permitiu sumar tres pezas á ducia conservada baixo a signatura de Lourenzá do AHN, e ofrece a transcrición de 15 documentos, 10 deles inéditos, reunindo o importante e elocuente conxunto de cartas de foro e licenzas de poboación con que o mosteiro documentou a súa política repoboadora. Acompáñase dunha aproximación tipolóxica.

Palabras Clave: Mosteiro, Lourenzá, cartas de xurisdicción, licenzas de poboación.

\section{AD POPULANDUM LICENCES AND CHARTERS FROM LORENZANA MONASTERY. A CONTRIBUTION TO THE CORPUS OF GALICIAN RURAL CHARTERS}

\begin{abstract}
The knowledge of the intense process of social and economic re-organization produced since mid 13th century in eastern Marina (Galicia) relies on the abundant number of fueros of the Cistercian monastery of Santa María de Meira. However, it can be argued that -due to the random path of its funds-, the remarkable documentary set of the Benedictine monastery of Salvador de Vilanova de Lorenzana (which is, to a certain extent, a replica of the previous one) has remained unnoticed. The known references, besides their unavoidable fragmented nature, frequently include transcription and date flaws that come to twist their testimonial usefulness. The work, resulting from a complex heuristic task in several fields, has allowed to add three items to the twelve already conserved under the signature of Lorenzana's National Historical Archive, and offers the transcription of 15 documents (12 of them unpublished), gathering the remarkable and eloquent set of fueros and population charters with which the monastery documented its population policy. A typological approach is also provided.
\end{abstract}

KEY WORDS: Municipal laws, charter of repopulation, monastery, Lorenzana 
Recibido/Received: 25/06/2013

Aceptado/Accepted: 19/08/2013

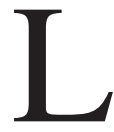

os fueros locales se significan como un centro de interés ya clásico que, hundiendo sus raíces en el siglo XIX y con acercamientos confluyentes desde diversas áreas de estudio, ha sido preferentemente dominio de historiadores del Derecho y medievalistas. Dentro de ellos, configuran un grupo propio aquellos que establecen las condiciones de vecindad y usufructo sobre una propiedad agraria, resultando un contrato enfitéutico completado con diversas cláusulas jurisdiccionales propias del derecho público. Su labilidad como instrumento adaptable a las circunstancias, eventual, conlleva una caracterización un tanto incierta, que unos han denominado "cartas de población", como tránsito entre la carta puebla y el foro, otros "fueros de población"1, también "fueros agrarios" y, al fin, "foros de población" o "foros concejiles"2.

\footnotetext{
1 Para los colectores monásticos del siglo XVIII cuyas notas figuran al dorso de los pergaminos eran "cartas de foro y población". Subrayó su carácter mixto José Villamil y Castro, Los foros de Galicia en la Edad Media, Madrid, Tip. Sucesores de Rivadeneyra, 1884, pág. 48, aunque, no obstante, las calificó de "cartas puebla". Después fueron denominadas "cartas de población" por Emilio Sáez Sánchez, "Cartas de población del Monasterio de Meira", Anuario de historia del derecho español, 14 (1943), págs. 500-518. Años después, Alfonso García Gallo renunció a distinguir por el contenido fueros y cartas puebla y puso el acento en la causa de concesión. Cf. del mismo "Aportación al estudio de los fueros", Anuario de historia del derecho español, XXVI (1956), pág. 420. Posteriormente Font Rius precisa su denominación como "cartas de población y franquicia" pero distinguiendo modalidades como "licencias ad populandum", "pactos agrarios colectivos" o "establecimientos aldeanos". Cf. José María Font Rius, Cartas de población y franquicia de Cataluña, vol. I, Madrid, CSIC, 1969, págs. XXII-XXV. Para el ámbito del noroeste es clarificador el estudio de Juan Ignacio RuIZ de LA PEÑa Solar, "Fueros agrarios asturianos del siglo XIII", Asturiensia Medievalia, 4 (1981), págs. 132-196.

2 Dolores Mariño aporta interesantes matizaciones al estudiar los documentos del monasterio de Meira, proponiendo la denominación de "foros concejiles" sobre la pionera sugerencia de "foros de población" de Villamil y Castro: Dolores Mariño VeIras, Señorío de Santa María de Meira (s. XII-XVI), A Coruña, Ediciones NOS, 1983, pág. 180. Con todo, no parece estar resuelto; combina después ambas denominaciones — cartas puebla y cartas de población— Javier Alvarado Planas, "Fueros y cartas pueblas inéditas de Galicia", Anuario de Historia del Derecho, 67 (1997), págs. 142-152; y aún recientemente, en un intento de compendio, se recurre a una ambigua rúbrica de "textos forales" entre los que se sitúan las "cartas de población" de Meira publicadas por E. Saez; vid. Faustino Martínez Martínez, "Antología de textos forales del Antiguo Reino de Galicia (siglos XII-XIV)", Cuadernos de Historia del Derecho, 10 (2003), pág. 276 y 294 y ss.
} 
En Cataluña y en el noroeste peninsular, y particularmente en Galicia, fue frecuente ese tipo de instrumento contractual que documenta una importante modalidad de un intenso proceso de colonización interior que, a la postre, acabó definiendo buena parte del paisaje agrario posterior.

En el caso gallego, y muy concretamente para el ámbito territorial que nos ocupa, su trascendencia fue señalada por Pegerto Saavedra, en su estudio de la provincia de Mondoñedo, contrastando las apreciaciones de Mariño Veiras sobre el dominio monástico de Santa María de Meira ${ }^{3}$. Ambos coinciden en la importancia de esa práctica contractual de asiento de pobladores que, en el caso de Meira, acabó cobrando personalidad propia en la historiografía como "Grupo foral de Meira"4.

Tal denominación alude en realidad no a todos los contratos de ese tipo otorgados por el monasterio, como muy bien señaló en su día Mariño Veiras, si no tan sólo a once de un total de veintitrés celebrados en el exacto arco temporal de cien años, desde 1234 a 1333. La misma autora advirtió en su día un reparto de áreas de influencia repobladora entre Meira, Lorenzana y el cabildo de Mondoñedo ${ }^{5}$, esquema que en nuestra opinión es resultado de una compleja dialéctica entre los respectivos dominios en la que estas cartas en ocasiones cumplirían la función de necesario reajuste. A modo de ejemplo puede citarse la conocida repoblación de Monte de Rúa ${ }^{6}$, que a la vez sirve para reordenar el poblamiento de las inmediaciones de Vilanova de Lorenzana, o la pionera en $1238 \mathrm{del}$ abad de Meira, Heimerico, sobre Vilar de Trabada, afectando precisamente a propiedades que habían sido de Lorenzana - hereditatis de Octeyra que fuit de Lorenzana ${ }^{7}$ - y que se apresuran a poblar de su mano. De estos ajustes abundan en testimonios los respectivos tumbos monásticos ${ }^{8}$.

3 Pegerto SaAvedra, Economía, política y sociedad en Galicia: la provincia de Mondoñedo, 1480-1830, Madrid, Consellería da Presidencia, Xunta de Galicia, 1985. Dolores Mariño VeIRAS, op. cit.

4 A partir de la edición parcial de 11 documentos por Emilio SÁEZ en op. cit.y del estudio posterior sobre los mismos de Justiniano Rodríguez Fernández, "Grupo foral de Meira, (Lugo)", Rev. Archivos Leoneses, 63 (1978) págs. 65-80. Recoge la denominación Faustino MARTínez Martínez, op. cit. pág. 294.

5 Dolores Mariño VeIras, op. cit. pág. 183.

6 En nuestra opinión el motivo de establecer la obligación de abandonar el solar original que se impone a los vecinos de Lorenzana que acudan al nuevo asentamiento es liberar las propiedades del coto. No obstante, también ha sido interpretado como mecanismo para asegurar la continuidad de la empresa repobladora. Cf. Ricardo Pena Domínguez, "Población del Monte de Rúa”, Estudios Mindonienses, 11 (1995), págs. 394.

7 Edita Emilio SáEz Sánchez, op. cit., págs. 501-502.

8 Excede las posibilidades de este artículo el análisis conjunto del fenómeno que estamos señalando. Sirva a modo de elocuente ejemplo: "Era de 1286 avía pleito entre este monasterio y el de Villa Nova de Lorençana en raçón de ciertas heredades y vasallaje de Tablada, y de mandato de don 
En el caso que nos ocupa, la actividad repobladora de los monjes de Lorenzana arranca en 1248, manifiesta su mayor intensidad en el tercer cuarto del siglo XIII y se interrumpe en la siguiente centuria para resurgir, y en eso constituye una excepción respecto a sus paralelos, con cuatro interesantes contratos durante el siglo XV.

Si bien, felizmente, todos ellos se conservan en el AHN, la azarosa trayectoria de los documentos que conforman el que, con justificado paralelismo, podríamos considerar "grupo foral de Lorenzana" refleja sin duda los avatares diversos que debieron correr los fondos monásticos tras la desamortización. Así, el otorgado sobre la heredad de Rega en 1265 figuró un tiempo entre los del monasterio zaragozano de Piedra, como atestiguan sus notas dorsales, mientras los restantes, sin duda por la recurrencia toponímica habitual, acabaron separados en dos fondos: unos bajo la titularidad original de San Salvador y tres — los de Cillero, Miñotelo y Villamariz - en los del monasterio cisterciense de Santa María de Villanueva de Oscos donde los hemos localizado9.

De esa singladura resulta una suerte dispar por la que hasta el momento han permanecido inéditos diez de ellos. Es bien conocido el de Monte de Rúa, y cuatro de los restantes se han dado a conocer - tres de ellos en el siglo XIX-en transcripciones con abundantes lagunas que trasladan inevitablemente errores de transcripción de las copias realizadas por los colectores monásticos del siglo XVIII cuyos regestos se consignan al dorso de los pergaminos. Las referencias tangenciales del meritorio y pionero trabajo sobre los foros gallegos de Villamil y Castro, así como los regestos del Libro Índice del monasterio ${ }^{10}$, han nutrido las escasas aproximaciones al conjunto si bien han trasladado la confusión cronológica que evidencian — confundiendo en muchos casos la Era hispánica-, y aun así han permanecido sin cita ni referencia alguna dos de los diplomas, el de 1269 otorgado sobre Meirengos y el de 1447 relativo al entorno de San Martín de Galgao.

Rodrigo Gómez ricohome y de dona Mayor Afonso su mujer se conçertaron y comprometieron en manos de tres hombres buenos, los quales mandaron que el abbad y convento de Villa Nova ${ }^{209 v^{\circ}}$ de Vila Nova no tengan ni posean ni adquieran ninguna hacienda ni vasallos en la villa de Tablada, sacando la villa de Órrea por sus términos, y que la que tenía el dicho monasterio de Lorençana en Trabada do diçen Los Trovos la dejasen al monasterio de Meyra y que, en recompensa, les diese el monasterio de Meyra tres partes unius serviçialis en Francos con un casal entero que se diçe Portiçelo." AHN, Tumbo de Meira, Clero, códice 114, fol, 209r ${ }^{\circ}$.

9 Nos hemos ocupado de la colección diplomática de este monasterio, muy relacionado no obstante con los de Meira y Lorenzana, en nuestro reciente trabajo, Colección diplomática de Santa María de Villanueva de Oscos (1139-1300), Oviedo, RIDEA, 2011.

${ }^{10}$ Índice de documentos del monasterio de San Salvador de Lorenzana, AHN, Clero, L. 6622. El trabajo de Villamil y Castro, vid. op. cit. 


\section{DESCRIPCIÓN Y TIPOLOGÍA}

Materializados la mayoría como documentos sinalagmáticos, la estructura más usual del articulado es la consignación nominal de los destinatarios y el lugar y derechos afectados, a la que sigue la estipulación de una renta, casi siempre de carácter mixto, en dinero, grano variado — centeno, trigo, cebada, escanday animales, — siempre gallinas y ocasionalmente algún ganado menor- En este apartado aparecen ya desdibujados los perfiles de lo público y lo privado, pues es frecuente la inclusión de conceptos propios del señorío, como la comenda o el obsequio del abad y la obligación de mostrar obediencia como vasallos. Sin solución de continuidad se aborda la exención de otras obligaciones forales y la concesión al concejo vecinal que se instituye de la mitad de la cuantía de las penas por alterar la vecindad —en el siglo XIII rapto, alevosía, hurto y homicidio, que en el XV se ha transformado en rapto, cuchilladas, hurto y avantadi$z o$ - Es frecuente la exención de las visitas de oficiales y también la concesión de la facultad de proponer alcaldes. Ocasionalmente se exime expresamente de luctuosa, nuncio y mañería. Finalmente se atiende a la posibilidad de acoger más familias en cada plaza y las condiciones para ello, entre las que es recurrente el pago de dinero en concepto de fumádiga u ocupación de solar.

Más interesantes resultan las que, siguiendo a Font Rius, hemos clasificado como licencias ad populandum ${ }^{11}$, y constituyen muestra temprana de la institucionalización del fenómeno del subforo. En el caso de Miñotelo, en 1253, el monasterio fija las condiciones con intermediarios para que éstos establezcan pobladores. Unos años después, en 1265, ese articulado resuena en la carta foral concedida a dos matrimonios sobre la heredad de Rega, abriendo la posibilidad de que pueblen ellos o instalen a otros; y en 1269, en Meirengos, se produce un curioso contrato que instala vitaliciamente un intermediario en varias servicialías de las cuales algunas parecen pobladas. En el caso de Montouto de Cadavedo en 1400 el mecanismo es idéntico al de Miñotelo, aunque los intermediarios asumen el compromiso de invertir en la edificación del caserío de las tres plazas y su dotación.

En relación con estas se encuentran las postreras cartas de este grupo. La de 1447 constituye un complejo entramado en el que se entrevé el subforo, concediendo al tiempo al mismo destinatario el contrato y la condición de intermediario con otros pobladores en el entorno de San Martín de Galgao. La de 1457 sobre el lugar de Caende y la de 1463 sobre el de Braña, evidencian un carácter mixto en tanto que los beneficiarios pueden poblar o "dar quien lo pueble".

\footnotetext{
${ }^{11}$ José María Font Rius, op. cit., págs. XXII-XXIII.
} 
En definitiva, el conjunto constituye un variado muestreo de textos forales locales, con una interesante casuística subyacente que abre posibilidades al estudio comparado del fenómeno de la repoblación de los dominios jurisdiccionales monásticos en el amplio entorno de la confluencia asturgalaica sobre la que proyectaron su influencia secular los monasterios de Meira, Oscos y Lorenzana.

\section{DOCUMENTOS $^{12}$}

1248, abril, 24

El abad Pedro y el convento del monasterio de Vilanova de Lorenzana entregan a Juan Rodríguez, Martín García y Pedro Pérez el monte y heredad de Santa Eulalia de Corquido con Pena de Couso para que lo pueblen en unión de Pedro Peláez, apodado Patel, quien lo hará en nombre del monasterio. Deberán ser vasallos obedientes y dar por foro anual de cada plaza, el día de San Martín, cinco sueldos, y como regueifa media tega de centeno, media de trigo y una gallina. Las penas de rapto, alevosía, hurto y homicidio serán compartidas entre los pobladores y el monasterio, y si alguno más entrase a vivir en una de esas plazas debe pagar un sueldo, media tega de cebada y una gallina.

A.- AHN, Clero, Lorenzana, carp. 1107, doc. núm. 10. Carta partida por ABC. Pergamino, 9,5 x $13 \mathrm{~cm}$.

Reg: Índice de documentos del monasterio de San Salvador de Lorenzana, AHN, Clero, L. 6622, fol. $7 \mathrm{r}^{\circ}$.

Cit. José Villamil y Castro, Los foros de Galicia en la Edad Media, Madrid, Tip. Sucesores de Rivadeneyra, 1884, pág. 7. Pegerto SAavedra, Economía, política y sociedad en Galicia: la provincia de Mondoñedo, 1480-1830, Madrid, Consellería da Presidencia, Xunta de Galicia, 1985, pág. 24.
A
B C
D E F
G $\quad$ H I
K

In dei nomine amen. Notum sit omnibus hominibus, tam presentibus quam futuris, quod ego Petrus, abbas Villenove de Laurenciana, unacum omni conventu eiusdem loci, damus ad populandum III hominibus scilicet Johannes Roderici et Martinus Garsía et Petrus Petri, et nos debemus ibi mittere alium populatorem per nos, videlicet Petrum Pelagii dictum Patel; illum nostrum montem et

\footnotetext{
${ }^{12}$ Se toman como referencia las normas de edición de la Comisión Internacional de Diplomática.
} 


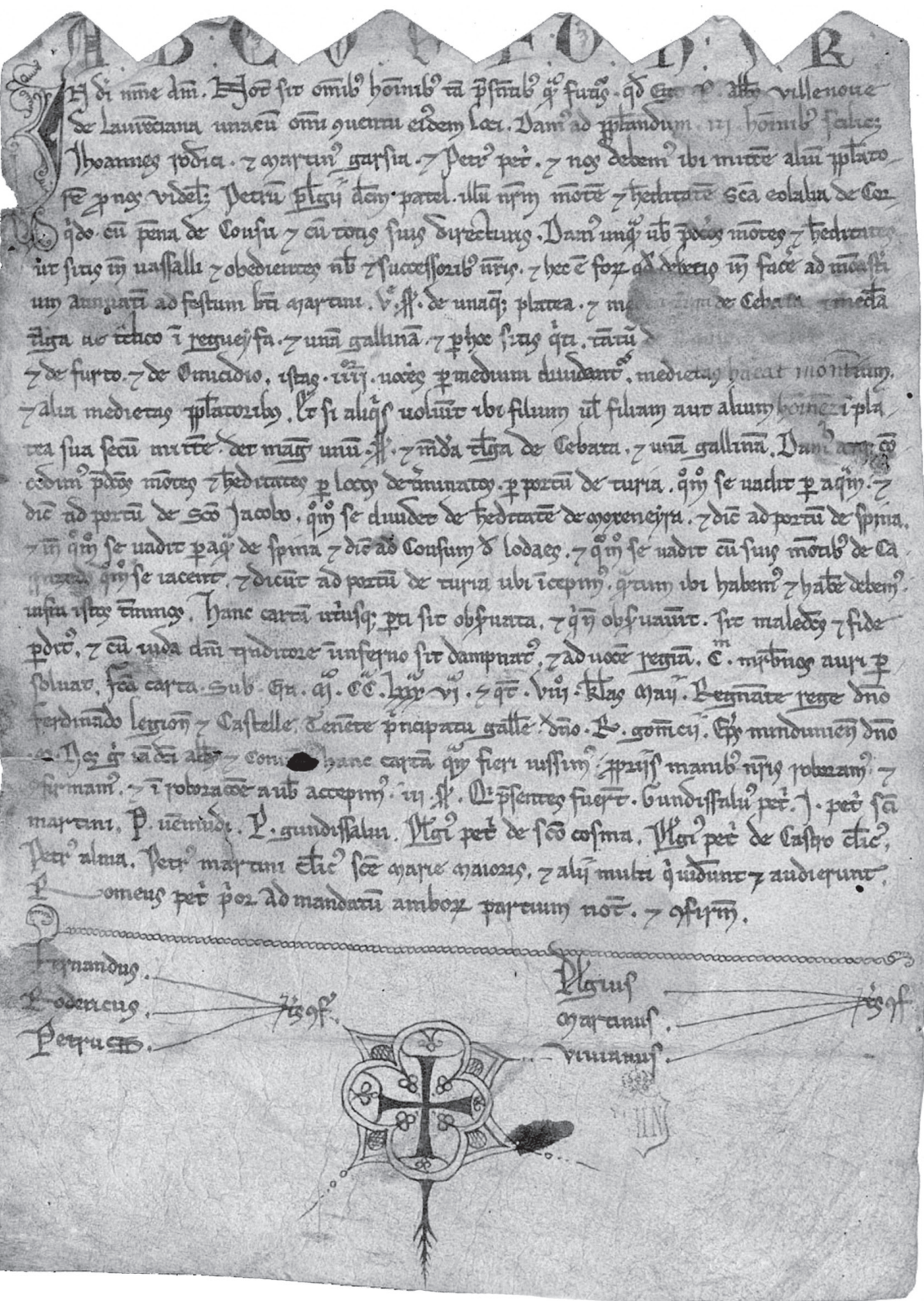

1

AHN, Clero, Carpeta 1107, núm. 10 
hereditatem Sancta Eolalia de Corquido, cum Penna de Cousu et cum totis suis directuris. Damus unumque vobis predictos montes et hereditates ut sitis inde vasalli et obedientes nobis et successoribus nostris, et hec est forum quod debetis inde facere ad monasterium annuatim ad festum beati Martini: Ve solidos de unaque platea et medea talega de cebata et medea talega de tritico in regueyfa et unam gallinam, et per hoc sitis quiti tantum $d$ [e rauso et de alevoysia] et de furto et de omicidio. Istas IIII $^{\text {or }}$ voces per medium dividantur, medietas habeat monasterium et alia medietas populatoribus. Et si aliquis voluerit ibi filium vel filiam aut alium [hominem] in platea sua secum mittere det magis unum solidum et media talega de cebata et unam gallinam. Damus atque concedimus predictos montes et hereditates per locos determinatos: per portum de Turia, quomodo se vadit per aquam et dicunt ad portum de Sancto Jacobo, quomodo se dividet de hereditatem de Moxeneyra et dicunt ad portum de Spina, et inde quomodo se vadit per aqua de Spina et dicunt ad Cousum de Lodaes et quomodo se vadit cum suis montibus de Carrazedo quomodo se iacent et dicunt ad portum de Turia ubi incepimus, quantum ibi habemus et habere debemus infra istos términos. Hanc cartam utriusque parti sit observata et qui non observaverit sit maledictus et fide perditus et cum Iuda domini traditore in inferno sit dampnatus et ad vocem regiam $\mathrm{C}^{\mathrm{m}}$ morabitinos auri persolvat.

Facta carta sub Era $\mathrm{M}^{\mathrm{a}} \mathrm{CC}^{\mathrm{a}} \mathrm{LXXX}^{\mathrm{a}} \mathrm{VI}^{\mathrm{a}}$ et quotum $\mathrm{VIII}^{\circ}$ kalendas maii. Regnante rege domino Ferdinando Legione et Castelle. Tenente principatu Gallecie domino Roderico Gomecii. Episcopo minduniense domino Martín.

Nos igitur iamdicti Abbas et conv[entum] hanc cartam quam fieri iussimus propriis manibus nostris roboramus et confirmamus et in roboracione a vobis accepimus III solidos.

Qui presentes fuerunt: Gundissalvus Petri, Johan Petri Sancti Martini, Petro Vermudi, Petro Gundissalvi, Pelagius Petri de Sancto Cosma, Pelagius Petri de Castro, clericus, Petrus Alma, Petrus Martini clericus Sancte Marie Maioris, et alii multi qui viderunt et audierunt.

Romeus Petri, prior, ad mandatum amborum partium notuit et confirma. (S)

Fernandus, testis, confirmat; Rodericus, testis, confirmat; Petrus, testis, confirmat.

Pelagius, testis, confirmat; Martinus, testis, confirmat; Vivianus, testis, confirmat. (S) 
1250, febrero, 13.- Vilanova de Lorenzana.

Juan II, obispo de Mondoñedo, en su nombre y en el del cabildo de su iglesia, por una parte, y don Rodrigo Gómez y doña Mayor Afonso en su nombre y en el del monasterio de Vilanova de Lorenzana por otra, a medias, ofrecen 250 plazas en el monte de Rua para los vasallos del obispo en toda su tierra, y para los de don Rodrigo en el valle de Lorenzana con tal de que dejen su casería equipada. Cada uno habrá de entregar cuatro sueldos por San Martín y dos sueldos por vita, cebada y colecta. Las penas de homicidio, rauso, hurto y alevosía se repartirán a tercias entre el obispo, don Rodrigo y el concejo y alcaldes de los vecinos, dividiendo el resto de las penas según el fuero de Benavente. El obispo se reserva los dos tercios de los derechos parroquiales futuros siendo el tercio restante para don Gómez y a su muerte para el monasterio. Para la iglesia que se construya se reservan dos plazas y sus respectivas tierras y derechos, y dos para el servicio del obispo y otras dos para el de don Gómez y el monasterio.

El concejo debe presentar el primero de enero de cada año diez hombres para que de entre ellos los señores elijan dos jueces y dos alcaldes.

Son libres quienes quieran de circular por tierra y de hacerse a la mar a pescar o enviar mercancías.

B.- AHN, Clero, Lorenzana, carp. 1107, doc. núm. 11. Pergamino, 9 x $25 \mathrm{~cm}$.

Reg.: Indice de documentos..., fol. 21ro. Tomás MuÑoz y Romero, Colección de fueros y cartas pueblas de España. Catálogo, Madrid, Imprenta de D. José Ma Alonso, 1852, págs. 201-2.

Edita: Eduardo de Hinojosa, Documentos para la historia de las instituciones de León y Castilla, Madrid, Centro de Estudios Históricos, 1919, pág.155. Ricardo Pena Domínguez, "Población del Monte de Rúa", Estudios Mindonienses, 11 (1995), págs. 387-400.

Cit.: Dolores Mariño Veiras, Señorío de Santa María de Meira (s. XII-XVI), A Coruña, Ediciones NOS, 1983, págs. 181-2. Ana María Barrero García y María Luz Alonso Martín, Textos de derecho local español en la Edad Media. (Catálogo de fueros y costums municipales), Madrid, CSIC, 1989, pág. 572.

Noverint universi ad quos presens pagina pervenerit quod Nos Johannes secundus, divina miseratione episcopus minduniensis, de voluntate et assensu decani et capituli ecclesie nostre, nomine nostro et ecclesie nostre, et Nos domnus Rodericus Gometii et domna Maior Alfonsi, pro nobis et pro voce nostra, et pro monasterio de Villa Nova de Laurenciana, polulamus per medium montem de Rua tali modo, scilicet: quod sint ducenti et quinquaginta populatores et quilibet populator dabit nobis episcopo et successoribus nostris et nobis domno Roderico 
Gomez in tota vita nostra et post mortem nostram abbatis et conventus monasterii supra dicti quatuor solidos usualis monete in festo Sancti Martini et duos solidos pro vita et pro cebata et pro collecta. Et de rauso et de omicidio et de furto et de aleyvosia dabunt nobis episcopo et successoribus nostris tertiam partem, et aliam tertiam nobis domno Roderico et voci nostre, et aliam tertiam habebunt concilium et alcaldes. Omnes alie voces dividantur secundum forum de Benavento. Et nos episcopus et domnus Roderico et sucessores nostri habe $>$ bi $<$ mus terciam partem et concilium terciam et alcaldes aliam terciam et huius voces tratentur secundum forum de Benavento. Omnes vero alii redditus ipsius loci et collecta inter nos episcopum et successores nostros et nos domnum Rodericum et vocem nostram per medium dividentur. Et per hoc erunt quiti et liberi de ${ }^{13}$ tota alia fazendeyra et de toto foro in ipso loco, tam ipsi quam omnes alii quos receperunt secum in suis placiis; et nos episcopus et successores nostri debemus habere duas partes redditus vel tributi et juris patronatus ecclesie vel eclesiarum quam vel quas ibi edificaverimus. Et nos domnus Rodericus in vita nostra, et post mortem nostram abbas et conventus supradicti monasterii, aliam terciam. Et ecclesiam habebit duas plazas et quilibet populator habebit unam plazam cum suam portionem hereditatis. Et nos episcopus pro nobis et pro ecclesia nostra, et nos domnus Rodericus pro nobis et per voce nostra, et pro mo $<$ n $>$ asterio supra dicto, retinemus nobis quatuor plazas per medium dividendas pro labore nostro et pro palaciis nostris. Et nos episcopus volumus et concedimus totis hominibus de tota terra nostra et de nostro caritello. Et nos domnus Rodericus hominibus de Villa Nova et de Valle de Laurenciana qui libere et sine movicio veniant populare in dicto monte, dum modo dimitant sua casalia populata. Et nos et succesores nostri debemus omni tempore dictam populationem deffendere et amperare in terris nostris et alibi ubicumque potuerimus. Et si forte qui absit inter nos vel successores nostros orta fuerit aliquam contentione vel discordia non debemus propter hoc facere aliqui malum in illa populatione, sed semper manutenere et defendere illam. Concilium vero debet in quolibet anno Kalendis jenrii presentare nobis vel mandato nostro decem homines de ipso concilio de quibus eligemus duos judices et duos alcaldes qui faciant iusticiam in ipsa populacione. Et si nos vel aliquis de voce nostra contra hoc factum venerit pectet alteri parti mille morabitinos et reputetur iniuriuosus. Et super hoc nos episcopus por nobis et pro ecclessia nostra et nos domnus Rodericus pro nobis et pro vece nostra et por monasterio supradicto, damus et concedimus dictis populatoribus monte de Rua cum totis suis pertineciis e directuris. In super damus et concedimus ut si aliquis homo de ista populacione voluerit ad ina mare ingredere vel piscare vel de suo

\footnotetext{
$\overline{{ }^{13} \text { Repetido de }}$
} 
avere mittere sine ulo inpedimento quidquid voluerit facere faciat et aperuimos terram ut nec per nos nec per alios homines sedeant impediti eundi et redeundi.

In cuis rei testimonium presentem cartam sigillorum nostrum munimine facimus roborari.

Actum sub Era $M^{\mathrm{a} C C} \mathrm{C}^{\mathrm{a}} \mathrm{LXX} \mathrm{X}^{\mathrm{a}}$ VIII. Datum apud Villam Novam quotum idus februarii.

1251, noviembre, 5

El abad Pedro, y el convento del monasterio de Vilanova de Lorenzana, dan a poblar la servicialía de Cillero que obtuvo Pedro Barba a Juan Rodríguez, Fernando Ibáñez, Juan Martínez y Juan Dedo, y a sus esposas y sus descendientes, a perpetuidad, a condición de que sean vasallos y paguen cada uno anualmente el día de Navidad un maravedí, media tega de centeno y media de trigo como regueifa y una gallina. Las penas por hurto, homicidio, rapto y alevosía se repartirán a medias con los alcaldes, y si se acogiera en la plaza a álguien, sea o no hijo, habrá de pagar un maravedí.

B.- AHN, Clero, Lorenzana, carp. 1107, doc. núm. 12. Pergamino, 14,5 x $7 \mathrm{~cm}$.

Reg: Índice de documentos..., fol. 100r ${ }^{\circ}$.

Edita: José Villamil y Castro, Los foros de Galicia..., págs. 136-137.

Cit.: Pegerto SaAvedra, Economía, política y sociedad..., pág. 24.

In nomine domini nostri Ihesu Cristi. Notum sit omnibus tam presentis quam futuris quod ego domnus Petro Guterri abbas Ville Nove de Laurenciana, cum omni conventum monachorum eiusdem loci, damus ad populandum illam nostram servicialiam de Cellario quatuor hominibus, videlicet: Johannes Roderici, Fernando Iohannis, Johannes Martini, Johannes Dedo et uxoribus eorum et posteriti eorum iure hereditario per secula cunta. Damus illis eandem servicialiam ut populent eam et sint vasalli et obedientes nobis et successoribus nostris et dent nobis annuatim unusquisque singulos morabitinos monete legione et media talega de cibata et media talega de trictico in regueyfa per octavam et unam gallinam, et per hoc forum faciendo sint liberi et quieti de tota soldaricia tantum de furto et de homicidio et de rauso et de aleyvosia, istas quatuor voces per medium dividantur per alcaldem ipsius populantie. Damus et concedimus eis supradic- 
tam servicialiam sicut eam obtinuit Petro Barba, per ubicumque iaceat excepto si forte sint iam datum alicui ad forum aliquis de illa. Si colligerint secum filium aut filiam sen quemlibet in sua quarta parte det magis unum solidum et sint liberi et quieti. Et debent persolvere memorantum forum annuatim ad festum Nathalis domini.

Si quis contra hoc factum venire $>$ persumserit $<$ vel venerimus sit maledictus et periuris et ad vocem regiam $\mathrm{D}$ solidos persolvat carta uero nichilonimus in suo semper robore permanente.

Facta carta in Era $\mathrm{M}^{\mathrm{a}} \mathrm{CC}^{\mathrm{a}} \mathrm{LXXX} \mathrm{X}^{\mathrm{a}} \mathrm{VIIII}{ }^{\mathrm{a}}$ in quotum nonas novembris. Nos igitur iamdicti abbas et conventus hanc cartam quam fieri iussimus propriis manibus roboramus et confirmamus et pro roboratione a vobis accepimus $\mathrm{X}^{\mathrm{m}}$ solidos.

Regnante rege domno Fernando Legione et Castelle. Princeps Gallecie domnus Roderico Gomez. Episcopus Mindoniensis domnus Johan.

Qui presentes fuerunt: abbas et conventus, Fernandus Sancii, miles; Aldefonsus Martin, Petrus Fernandi, Dominicus Fernandi, Rodericus Gundissalvi, milites; Pelagio Fernandi, clericus; Domnus Petrus Vermudi, Martinus Iohannis et alii multi qui viderunt et audierunt.

Romeus Petri monachus et notario et confirmat.

Vivianus, testis, confirmat; Marchus, testis, confirmat; Pelagius testis, confirmat.

Rodericus, testis, confirmat; Johannes, testis, confirmat; Garsias, testis, confirmat.

(De otra mano) Este he o traslado da dicta carta que eu Affonso (S) Stevan racoeiro et notario público da yglesia de Mendonnedo, a rogo de Clemente Eanes clérigo de coro de Mendonnedo fige in mya presença scripvir et per mya mao propria in ella subscripvo e confirmo et meu nome et meu signal pono in testemunno de verdade.

Testes $0<\mathrm{s}>$ chantres do minduniense Martín, de San Martino Affonso Carneyro.

1253, diciembre, 25

El abad Pedro y el convento del monasterio de Vilanova de Lorenzana ceden a Juan Peláez y a Vivian Peláez, clérigos, a perpetuidad, la heredad de Miñotelo, a condición de que instalen allí dos pobladores que sean vasallos del monasterio 
que deberán pagar cada año por Navidad 10 sueldos, dos gallinas y una tega de cebada, siendo exentos de todo otro servicio y pena excepto las de rauso, hurto, homicidio y alevosía que repartirán con el monasterio.

A.- AHN, Clero, Villanueva de Oscos, carp. 1623, doc. núm. 1. Pergamino, 14,5 x 15,5 cm. Carta partida por ABC. Algunas manchas de humedad y dos raspaduras en el centro.

Reg: Índice de documentos..., fol. $104 \mathrm{r}^{\circ}$.

Edita: José Villamil y Castro, Los foros de Galicia..., págs. 137-138.

Cit.: Pegerto SaAvedra, Economía, política y sociedad..., pág. 24.

A B C

Inicium scripti fiat in nomine Cristi. Notum sit omnibus ominibus tan presentibus quam futuris quod ego Petrus, Dei gratia abbatis Ville Nove de Laurentiana, unacum omni conventu monachorum eiusdem loci, vobis Iohannes Pelagii et Vivian Pelagii clericis damus illam nostram hereditatem que vocitant de Miotelo, et iacet inter villam de Guarda et inter villam de Fictorio, illam nostram hereditatem quam nos ibi habemus per suis terminis et locis antiquis, per terminos novos et veteros. Damus eam vobis sub tali condictione: que vos debettis ibi mittere II $^{\text {os }}$ populatores et ipsi debent ere vasalli obedientes nobis et succesoribus nostris et debent dare annuatim ad monasterium in festo Natalis domini $\mathrm{X}^{\mathrm{em}}$ soldis monete legionensis et duas gallinas et una talega de cebata per octava, et per hoc forum faciendo debent ere liberi et quieti de tota fazendaria tantum de rauso, de furto, de omicidio e de aleyvosia, istas $\mathrm{IIII}^{\circ}$ voces per medium dividantur medietas habeat monasterium et alia medietas permaneat in populatores. Damus eam vobis ut habeatis vos et omni progeniei vostre in perpetuum iuri quieto, vendetis, donetis, faciatis de ea voluntatem vestram, tamtum que monasterio semper habeat suum forum in pace et fideliter sine ulla contradiçon et semper se vindicus per domnum abbatem.

$\mathrm{Si}$ quis [contra hoc] forum venerit vel venerimus sit maledictos et periuros et ad verificam partem $\mathrm{C}^{\mathrm{m}}$ aureos persolvant. Carta vero nichilominus in suo semper robore permanente.

Facta carta sub Era M $^{\mathrm{a}} \mathrm{CC}^{\mathrm{a}} \mathrm{LXL}^{\mathrm{a}} \mathrm{I}^{\mathrm{a}}$ et quotum VIII kalendas Januarii. Regnante rege domno Adefonso Legionis et Castelle. Obtinente principatu Gallecie domno R. Gómez. Antistite minduniense sedis domno J. Maiorino regis domno R. Suarii.

Nos quis iandictis concedimus et laudamus et promittimus totum fideliter observare et non debet ibi intrare maiordomus nec sagion. 
Qui presentes fuerunt: iam dicti abbatis et conventus, Pelagius Petri clericus de Pasturicia, Rodericus Garsie, Petrus Gundissalvi, Petrus Iohannis, Iohannes Iohannis, Pelagius Martini, Dominicus Facundi de Fictorio et alii multi videntes et audientes.

( $1^{a}$ columna) Petrus, ts. cf., Rodericus, ts. cf., Martinus, ts. cf.

$\left(2^{a}\right.$ columna) Fernandus ts. cf., Pelagius ts. cf., Vivianus ts. cf.

Romeus Petri, prior, notuit confirmat.

1254, febrero, 22

El abad Pedro y el convento del monasterio de Vilanova de Lorenzana aforan a Juan Rodríguez, a Martín Pérez y a las mujeres de ambos y a su descendencia, a perpetuidad, el lugar de Bolequeiro, que delimitan, que habrán de cultivar y poblar como vasallos del monasterio, por un canon anual de cinco sueldos, media tega de trigo, media de cebada y una gallina cada uno, pagadero por San Martín y por Pascua, quedando eximidos de la mitad de la cuantía de las penas de rauso, hurto, homicidio y alevosía.

A.- AHN, Clero, Villanueva de Oscos, carp. 1623, doc. núm. 7. Pergamino, 15 x 20,5 cm. Carta partida por ABC. Margen derecho deteriorado.

Reg: Índice de documentos..., fol. $6 \mathrm{r}^{\circ}$.

Cit.: José Villamil y Castro, Los foros de Galicia...,pág. 46. Pegerto Saavedra, Economía, política y sociedad..., pág. 24.

A B C

In Dei nomine amen. Notum sit omnibus hominibus qui viderint istam cartam quod nos Petrus abbatis Ville Nove de Laurenciana et totum eiusdem conventus damus ad populandam nostrum vilarem que vocitant Bolequeyra duobus hominibus, scilicet Johanne Roderici et Martinus Petri et uxoribus eorum et omni progeniei sue, damus ${ }^{14}$ ipsis per dicem Vilarem cum omnibus directuris suis tam de rivulo quam montes, exitus vel regresum eorum et cum omnia voci sue quam ibi habemus vel habere debemus per ubi cumque eam potuerint in-

\footnotetext{
14 Tachado: inque.
} 
venire. Damus ipsum vilarem per locos determinatos, videlicet: per pontem de molendini vetus ad Petram de cauti, quomodo se dividet per hereditatem de Villa Seca et inde vadit ad Penna de Coruena. Damus eam vobis, atque concedimus haec pernominatus vilarem tali tenore ut pobletis eam et hedificetis et plantentis et sitis de ea vasalli et obedientes nobis et sucesoribus nostris et detis inde nobis annuatim a monasterio iam dicto unumquisque vestrum $\mathrm{V}$ solidos monete legionem et singulas regueyfas de media talega de tritico per octava, et media talega de cibata et singulas gallinas. Et hoc forum debetis dare semper annuatim nobis et voci nostrem, medietatem ad festum Sancti Martini ${ }^{15}$ et aliam medietas ad festum Pasche. Et per hoc forum sitis liberi et quieti de omnibus vocibus IIII ${ }^{\text {or }}$ voces: furtum, omicidium, rausum et alleyvosiam, istas IIII $^{\text {or }}$ voces per medium dividantur, medietas habeant monasterium et alia medietas populatoribus, istut faciendo habeatis et posideatis vos et omni progeniei vestre in perpetuum.

Si qualquer tam de nostra parte quam de extranea ad istum factum presumserit sit maledictus et fide perditus et ad vocem regiam $\mathrm{C}^{\mathrm{em}}$ aureos persolvat et carta semper robur suum obtineat.

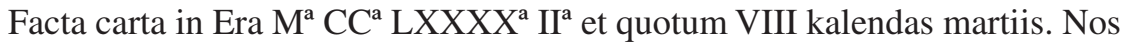
qui iam dicti abbatis et conventi haec cartam quam fieri iussimus propiis manibus roboramus et confirmamus et pro roboracione a vobis accepimus III solidos.

Regnante rege domno Adefonso. ${ }^{16}$ Tenente principatu Gallecie domno Roderico Gomez. Antistite sedis minduniensis domno Johan.

Qui presentes fuerunt Fernandus Fernandi et Petrus piliteyro, Martinus Pelaez de Souto, Johannus Roderici de Lastra et alii multi videntes et audientes.

Iohane Fernandi notuit (S.)

( $1^{a}$ columna) Johanne, ts.; Rodericus, ts.; Petrus, ts.

( $2^{a}$ columna $)$ Vivianus, ts.; Pelagius, ts.; Martinus, ts.

\section{6}

1257, febrero, 9

El abad Romeu, y el convento del monasterio de Vilanova de Lorenzana, con mandato de don Rodrigo Gómez, ofrecen a diez pobladores su heredad de Villar de Choy, a perpetuidad, para que sean vasallos y entreguen por foro, mitad por San Martín y mitad por Pascua, 3 sueldos cada uno y una colecta anual de un

\footnotetext{
${ }^{15}$ Tachado: medietatem.

${ }^{16}$ Repite: A.
} 
cerdo valorado en 6 sueldos, diez gallinas, tres carneros y cuatro tegas de cebada y sendas hogazas de centeno. Quien se acoja en el lugar habrá de pagar un sueldo por fumádiga, y participar con los demás en el pago del resto. Se regirán por sus alcaldes, y son libres de todas las penas excepto de rauso, hurto, alevosía y homicidio, que dividirán a medias con el monasterio.

A.- AHN, Clero, Lorenzana, carp. 1107, doc. núm. 17. Carta partida por ABC. Pergamino, $11 \mathrm{x}$ $11,5 \mathrm{~cm}$.

Reg.: Indice de documentos..., fol. $3 \mathrm{r}^{\circ}$.

Cit.: José Villamil y Castro, Los foros de Galicia..., pág. 46. Pegerto Saavedra, Economía, política y sociedad..., pág. 24.
A
B C
D $\quad$ E
$\mathrm{F}$
G H

Notum sit omnibus hominibus tam presentibus quam futuris quod ego Romeu, divina permissione abbatis monasterii Ville Nove de Laurenciana, unacum omni conventu monachorum eiusdem loci et auctoritate et mandato domini Roderici Gomecii, damus ad populandum illam nostram hereditatem quam vocatur Villar de Choy et jacet inter Farum de Gontan et Romariuz. Damus dictam hereditatem $\mathrm{X}^{\mathrm{m}}$ populatoribus ut sint vasallis nobis et successoribus nostris et unusquisquis det per foro nobis et successoribus nostris III solidos monete legionis et unam collectam anuatim scilicet de uno porco priciato de VI solidos et X gallinis et de tribus cabritis et IIII $^{\text {or }}$ taleguis de cibata per octava et de pane centeno singulas fugazas, et si fore aliquem vel aliquis secum collegerint unumquisquis debet nobis dare anuatim I solido per fumadiga et vita et cibata sicut aliis populatoribus. Et per hoc forum faciendo sint quiti et liberis de omnibus vocibus et de tota fazendeyra excepto de IIII $^{\text {or }}$ vocibus, scilicet de furto et de aleyvosia et de rauso et de omicidio. Istas IIII $^{\text {or }}$ voces per medium dividantur medietas habeat monasterium et medietas populatoribus, et de isto foro debent dare medietatem ad festum beati Martini et medietatem ad festum pascham. Et istam populationem semper se vindicare debet per alcaldes.

Nos predicti abbatis et conventus damus memoratam hereditatem per suos locos terminos et antiquos, videlicet: per carvalium de Catadoyro, sicut intrat ad portum de Cavada et inde per rivulum de Guaa sicut intrat ad Mestas d'Escourido sicut exit ad caminum de Gontan sicut intrat ad fontem de Albergaria vedra et sicut ipse fons intrat ad Mestas ${ }^{17} \mathrm{~d}^{\prime}$ Espinarcau et inde ad portum de Cubis sicut intrat et ad carvalum de Catadoyro ubi incipimus. Damus quantum ibi habemus vel havere debemus ad forum sicut supra scriptum est.

\footnotetext{
17 Tachado d'Escourido
} 


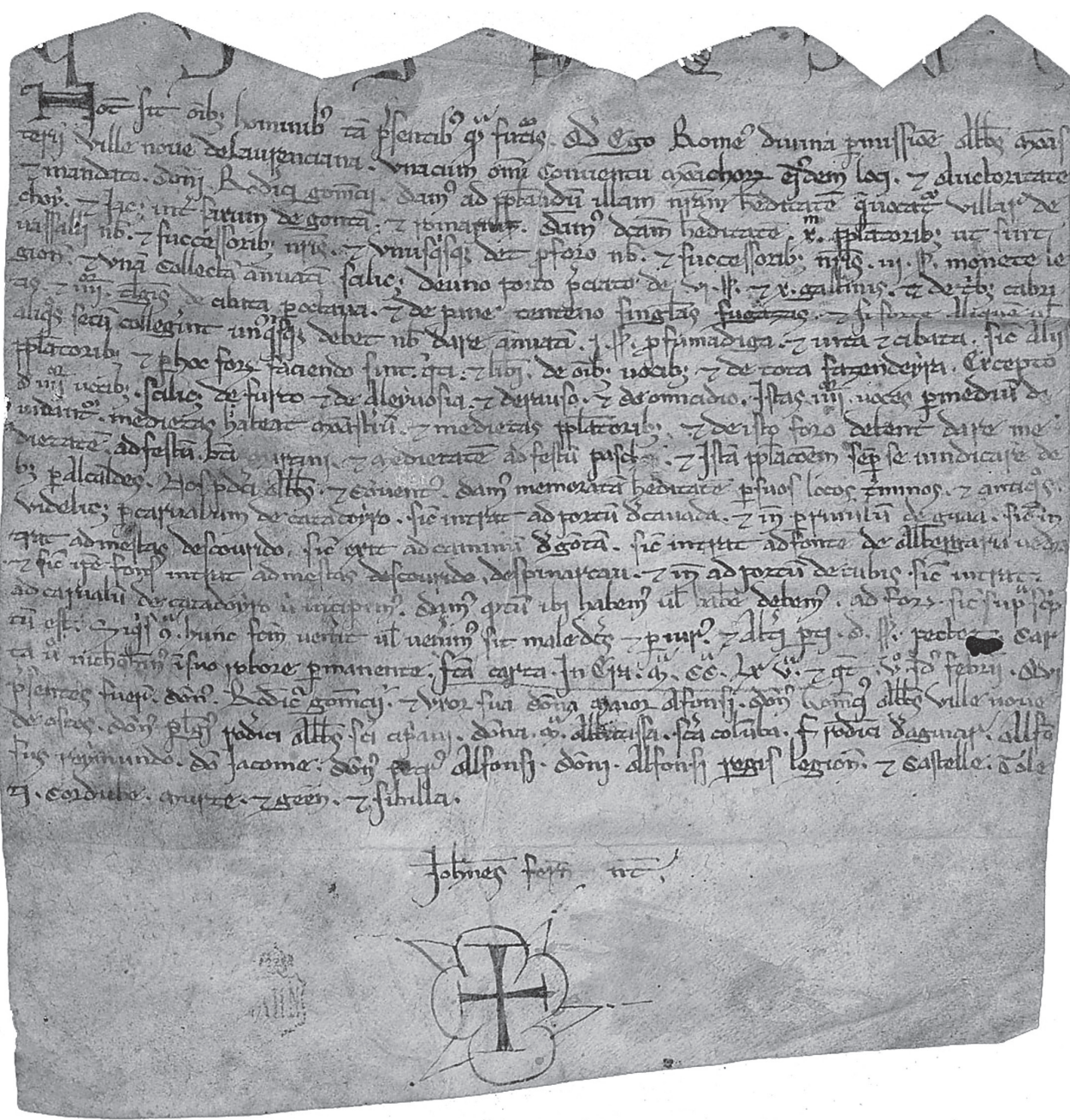

6

AHN, Clero, Carpeta 1107, núm. 17

Si quis contra hunc forum venerit vel venerimus sit maledictus et per iurum et alteri parti $\mathrm{D}$ solidos pectet et carta vero nichilonimus in suo robore permanente.

Facta carta in Era $\mathrm{M}^{\mathrm{a}} \mathrm{CC}^{\mathrm{a}} \mathrm{LX}^{\mathrm{L}} \mathrm{V}^{\mathrm{a}}$ et quotum $\mathrm{V}^{\mathrm{o}}$ idus febrerii.

Qui presentes fuerunt: domnus Rodericus Gomecii et uxor sua domna Maior Afonsi; domnus Gomecius abbatis Ville nove de Oscos, domnus Pelagius Ro- 
derici abbatis Sancti Cipriani, domna María abbatissa Sancta Columba, Fernán Roderici de Aguiar, Alfonsus Reymundo, don Jacome, domnus Petrus Alfonsi.

Domini Alfonsi regis Legionem et Castelle, Toleti, Cordube, Murze et Geen et Sibilla.

Johannes Fernándiz notuit. (S)

1265, diciembre, 30

El abad Romeu y el convento del monasterio de Vilanova de Lorenzana entregan la mitad de la heredad de Rega, que habían recibido de don Pelayo Fernández, a Martín Iohannis y su mujer Mayor Martínez, y a Fernando Martínez y su mujer María Peláez, a perpetuidad, exceptuando lo que habían dado a Fernando Sánchez y sus descendientes, para que instalen alli dos pobladores que sean vasallos obedientes y paguen, mitad por San Martín y mitad por Pascua, cinco sueldos cada uno, y media tega por octava de trigo y media de cebada y una gallina por foro anual. Si acogen a álguien en la plaza habrá de pagar cierta cantidad de sueldos y sendas quartas de tega de trigo y de cebada. Serán libres de todo otro tributo y de nuncio, gayosa y mañería, así como de mayordomo o sayón, y serán gobernados por el abad o quien designe siendo exentos de penas, excepto las de robo, rauso, alevosía y homicidio que compartiran a medias con el monasterio.

A.- AHN, Clero, Lorenzana, carp. 1107, doc. núm. 18. Carta partida por ABC. Pergamino, 10 x 13 $\mathrm{cm}$. Ligeramente amputado el margen izquierdo, afectando al primer numeral de las centenas de la data, lo que provocó el error de un colector del siglo XVIII datándolo al dorso en la Era 1204. Grandes manchas de humedad y tinta diluida en diversos puntos.

Reg: Índice de documentos..., fol. 49 ro.

Cit.: José Villamil y Castro, Los foros de Galicia..., pág. 46.

A $B \quad$ C $\quad$ D $\quad$ E $\quad$ F

In dei nomine amen. Notum sit cuntis presentis videntibus quod ego Romeus, divina pretenssionem abbatis monasteerii Ville nove de Laurenciana, unacum omnium conventum monachorum siusdem loci, damus illam nostram hereditatem de Rega quam nobis et monasterio nostro dedit domnus Pelagius Fernandi, duobus populatoribus, videlicet Martinus Iohannis et uxori eius Maiori Martini et Fernando Martini et usori eius Marie Pelagii et filiis et filiabus eorum et omni 


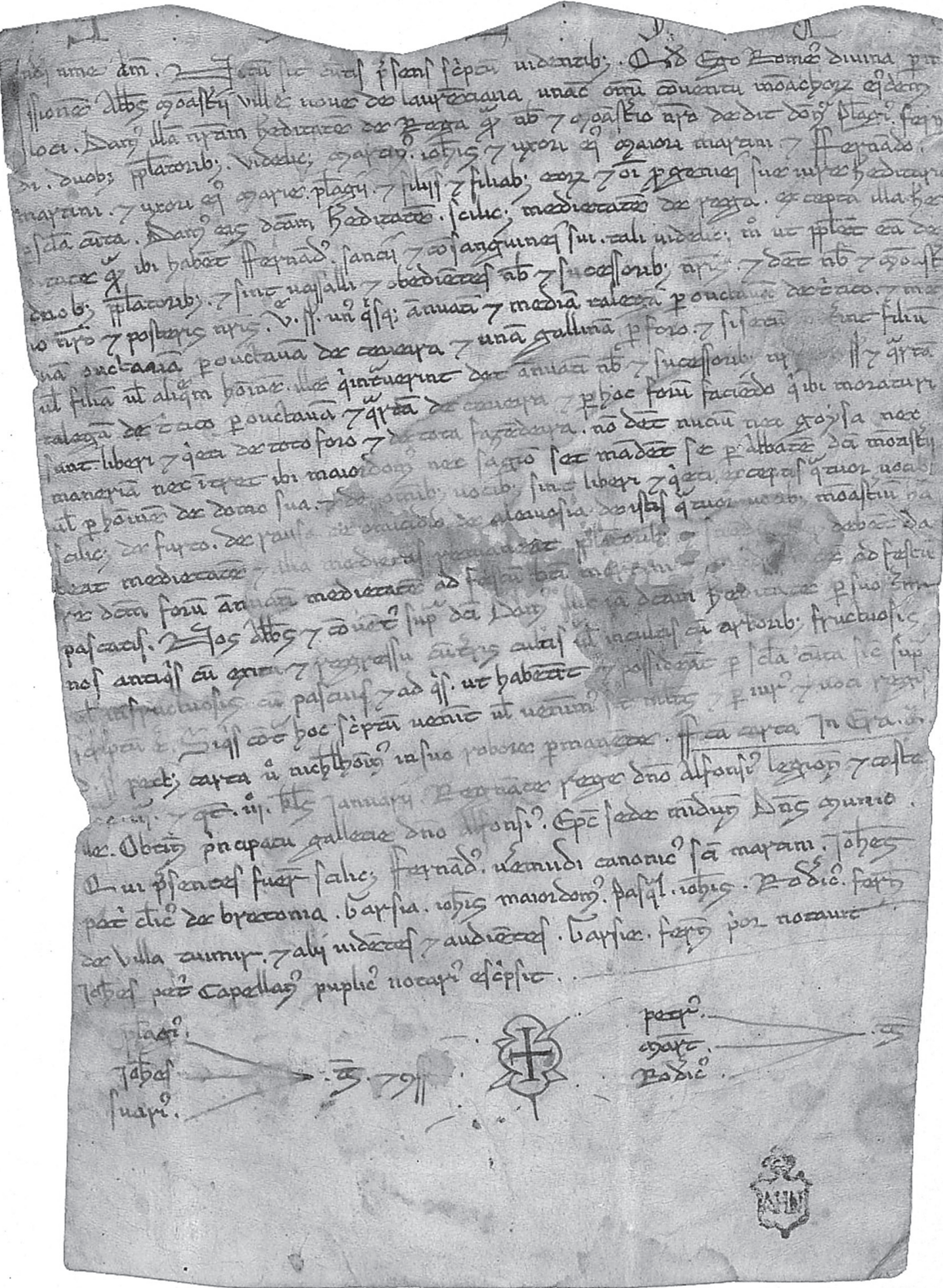

AHN, Clero, Carpeta 1107, núm. 18 
progenie sue iure hereditario per secula cunta. Damus eis dictam hereditetam scilicet medietatem de Rega excepta illa hereditate quam ibi habent Fernandus Sancii et consanguineis sui, tali videlicet modo ut populetis eam de duobus populatoribus et sin vasalli et obedientes nobis et sucessoribus nostris et detis nobis e monasterio nostro et posteris nostris Ve solidos unusquisqui annuatim et mediam talegam per ouctavam de tritico et mediam ouctavam per ouctavam de ceveira et unam gallinam per foro et si secum [...] int filium vel filiam vel aliquem hominem ille querintaverint det anuatim nobis et sucessoribus nostris [...] solidos et quartam talegam de tritico per ouctavam et quartam de ceveira et per hoc forum faciendo qui ibi moraturi sunt liberi et quieti de toto foro et de tota fazendeira, non dent nuncium nec goisa nec maneriam nec intret ibi maiordomus nec sagion set mandent se per abbatem dicti monasterii vel per hominem de domo sua et de omnibus vocibus siat liberi et quieti exceptis quatuor vocibus, scilicet: de furto, de rauso, de omicidio, de aleivosia; de istis quatuor vocibus monasterium habeat medietatem et alia medietas remaneat at populatoribus et sciendum que debent dare dictum forum annuatim medietatem ad festum beati Martini [et medietatem] ad festum pascatis.

Nos abbas et conventus supradicti damus illis predictam hereditatem per suos terminos antiquis cum exitu et regressu cun terris cultis vel incultis cum arboribus fructuosis vel infructuosibus, cum pascuis et ad quis ut habeatis et possideatis per secula cunta sive suprascriptum est.

Siquis contra hoc scriptum venerit vel venerimus, sit maledictus et per iurus et voci regis $\mathrm{D}$ solidos pecte, carta vero nichilhomnibus in suo robore mermanente.

Facta carta in Era $\mathrm{M}^{\mathrm{a}}[\mathrm{C}] \mathrm{CC}^{\mathrm{a}} \mathrm{III}^{\mathrm{a}}$ et quotum $\mathrm{III}^{\mathrm{o}}$ kalendas Ianuarii. Regnante rege domno Alfonsius Legione et Castelle. Obtinente principatu Gallecie domno Alfonsius. Episcopus sede minduniense domnus Munio.

Qui presentes fuerunt scilicet: Fernandus Veremudi, canonicus Sancti Martini; Johannes Petri, clericus de Bretonia; Garsia Iohannis, maiordomus; Pasqual Iohannis, Rodericus Fernán de Villa Tuimir et alii videntes et audientes.

Garsie Fernán, prior, notavit.

Johannes Petri capellanus puplicus notarius escripsit.

Pelagius, testis et confirmat; Johannes, testis et confirmat; Suarius, testis et confirmat.

(S.)

Petrus, testis; Martinus, testis; Rodericus, testis. 
1267 , enero, 2

El abad Romeu y el convento del monasterio de Vilanova de Lorenzana entregan a Fernán Juanes y a su mujer María Juanes, a perpetuidad, su heredad en Vilar de Masma y otras que determina en el entorno para que hagan casal y la pueblen y den cada año por foro, por San Martín, cinco sueldos y tres duizimas de trigo y tres de cebada por la del burgo y una gallina, que repartirán abad y vestiario. Si álguien más se acoge al foro habrá de pagar un sueldo anual por fumádiga. Quedan exentos de mañería y gayosa y pagarán un máximo de cinco sueldos de nuncio.

A.- AHN, Clero, Lorenzana, carp. 1107, doc. núm. 19. Carta partida por ABC. Pergamino, 9,5 x 13 $\mathrm{cm}$. Manchas de humedad afectan a la escritura resultando ilegible en algún punto.

Reg: Índice de documentos..., fol. $9 \mathrm{r}^{\circ}$.

Cit.: José Villamil y Castro, Los foros de Galicia..., pág. 46. Pegerto Saavedra, Economía, política y sociedad..., pág. 24.

A $\mathrm{B} \quad \mathrm{C} \quad \mathrm{D} \quad \mathrm{E}$

Innume de dios amen. Cunuzuda cousa seia a quantos esta carta virin que eu dun Romeu, abbade do mesteyro de Villa nova de Laurenzáa, aiuntadamente conono ${ }^{18}$ conventu dese miismu logar damos a vos Fernán Iuhanes ea vossa muller María Iuhanes en toda vossa gearazón una nossa herdade que nos havemus in Vilar de Masma, comu se departe en deredor dos outros herdeyros e damus vos quantu nos havemus na terra de Pay Castela que iaz sua ponte de Murinaus e damus vos ouctra herdade aqual suya teer Pedro Celeyro por prestamo a que iaz en Prado. Damus a vos estas devan ditas herdades aatal foro que seiades delas vasalus eubidientes anos eaqueles que despús nos vieren [eno] nosso lugar e fazades casal en aquela herdade de Villar de Masma e dedes en cada anno por foro destas herdades ia ditas aa festa de San Martín cinquo sólidos e tres duyzimas de triigu e tres de cevada pela duyzima do burgu e una gallina e deste furu us tres soldos sun da vistiaria ea meatade de triigu ea meatade da cevada eos oustros dous soldos ea outra meatade do triigu e dacevada ea gallina seia do abbade. E seia quem quiserdes meter cunvosco para pubrar dem senos soldos cada ano por fumadiga. Eaqueles que y pubraren non den manninadigu nen goyosa e por nuzu nen den foras cinque soldos. Damus a elles de van ditos estas herdades de susuditas asi comu de susu razua por iur derdade por secula cunta e fazades delas

\footnotetext{
${ }_{18}$ Sic pro cono
} 
Weamenom

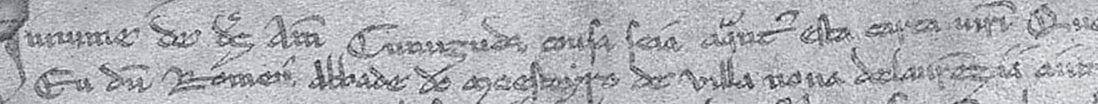

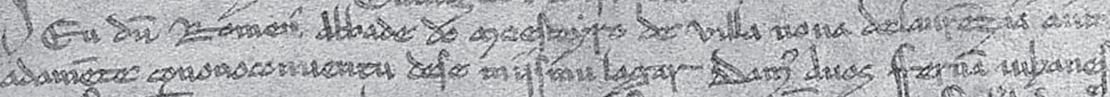

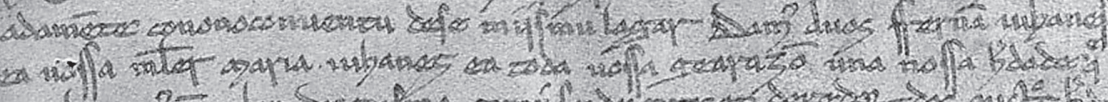

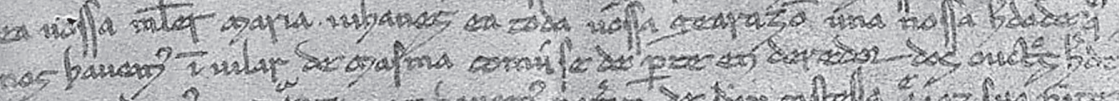

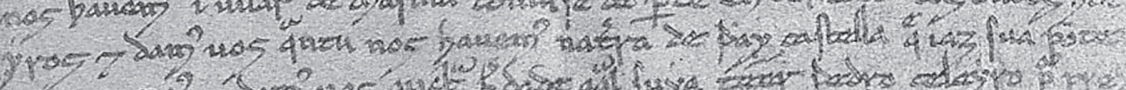

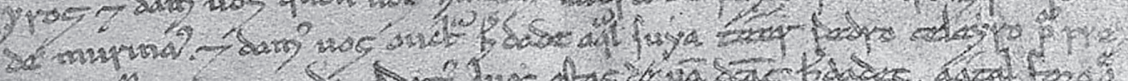

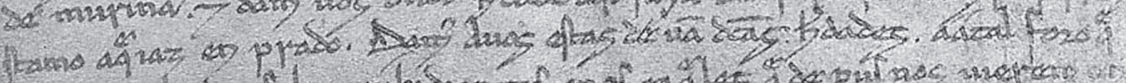

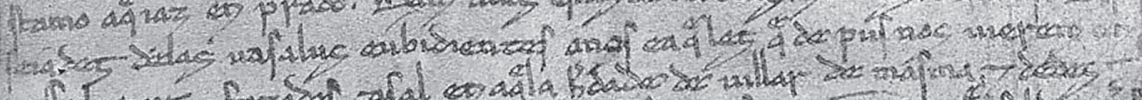

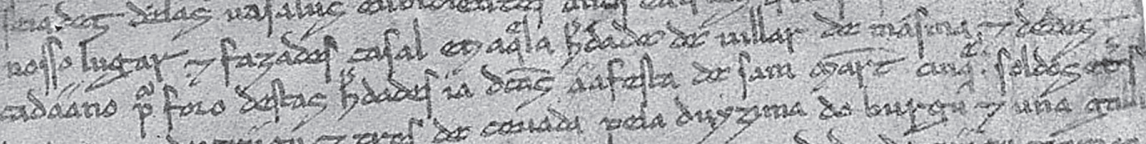

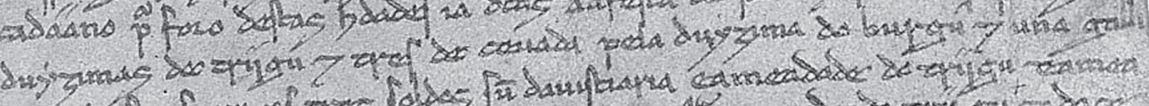

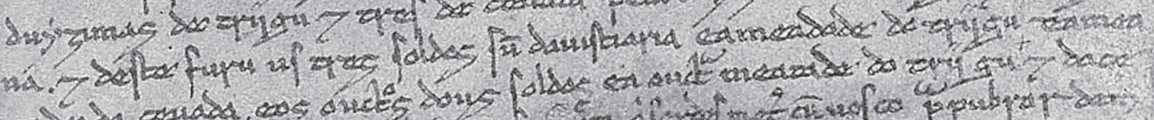

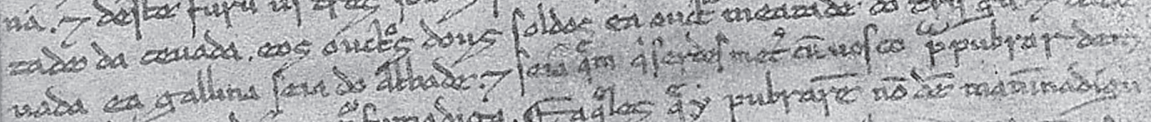

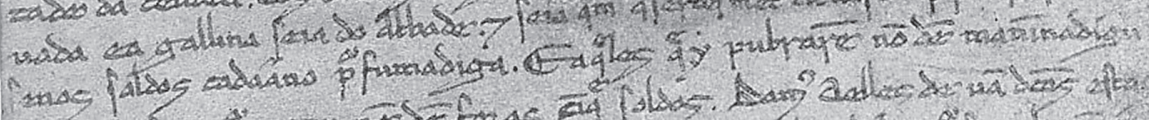

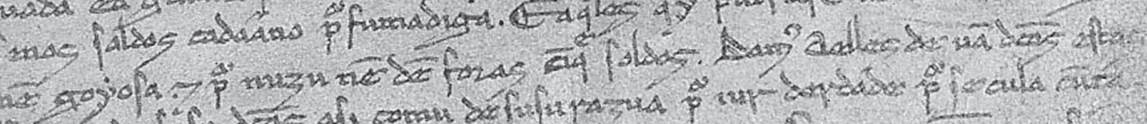

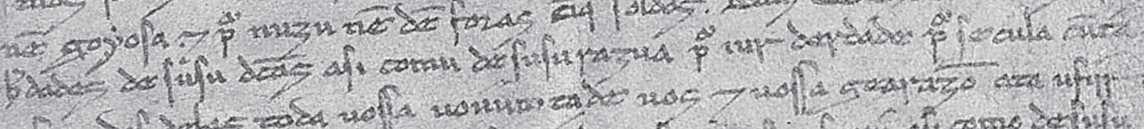

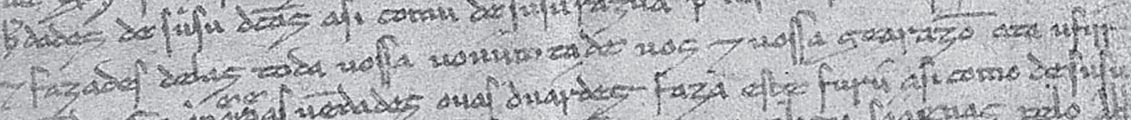

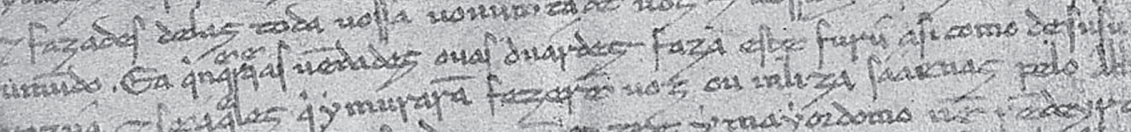

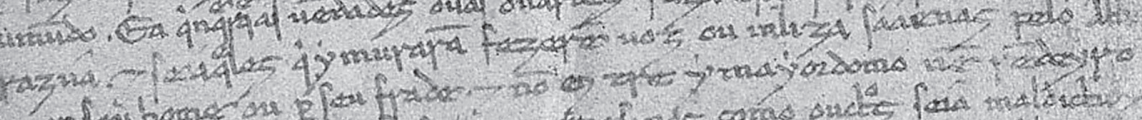

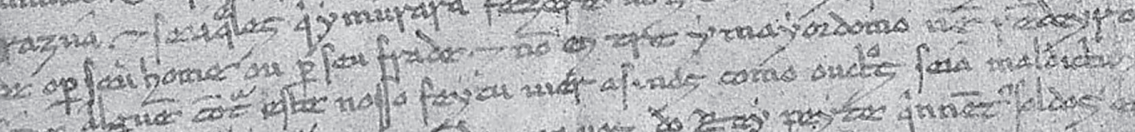

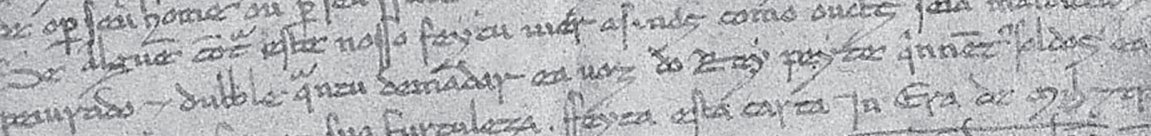

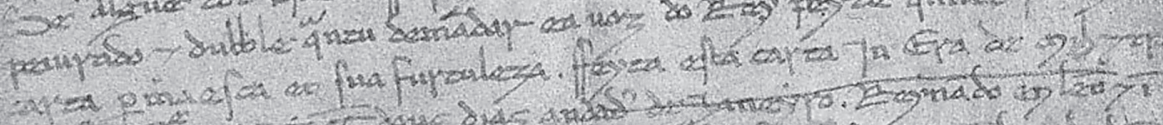

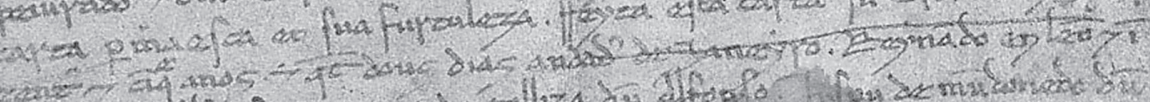

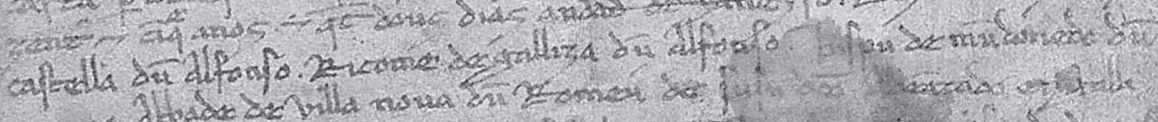

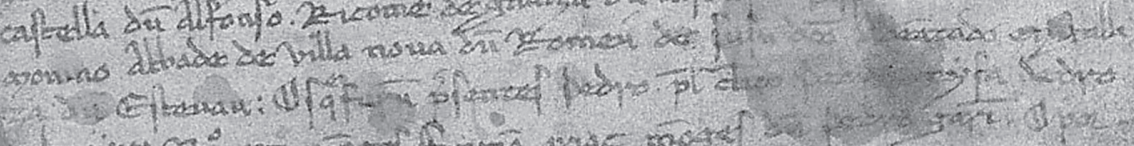

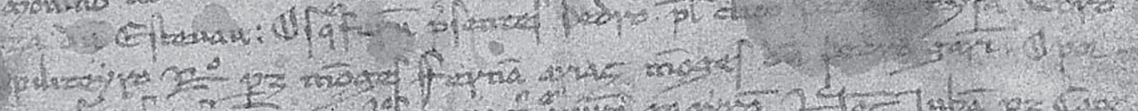

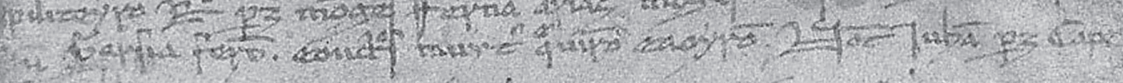

Hic sublimes morapro.

pastring:

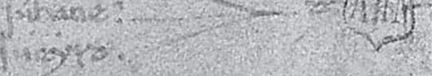
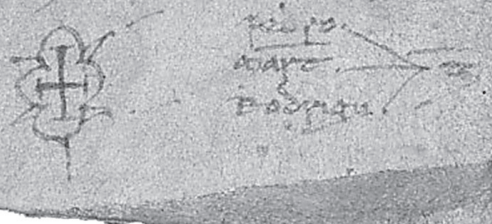

8

AHN, Clero, Carpeta 1107, núm. 19

Cuadernos de Estudios Gallegos, LX, núm. 126 (2013), págs. 85-123. ISSN: 0210-847 X. DOI: 10.3989/ceg.2013.126.03 
toda vossa vouumtade vos e vossa gearazón ata u fin [d]u mundo. Ea quien quer que as vendades ou as duardes faza este furu así como de susu razua, e se aqueles que y muraran fazeren voz ou inliza saaenas pelo abbade o per seu home ou per seu frade, e non entre y mayordomo nen rendeyro.

Se alguén contra este nosso feytu vier así nos como ouctros seia malditu e peiurado e dubble quantu demandar ea voz do rey peyte quinnentus sóldos ea carta permaesca en sua furtaleza.

Feyta esta carta in Era de Mil e treszentos e cinquo anos e quoto dous días andadus de Janeyro. Reynando en León e in Castella dun Alfonso. Ricome de Galliza dun Alfonso. Bispu de Mundonedo dun Monino. Abbade de Villa Nova dun Romeu de susu dito. [Ad]eantado en [G]alliza dun Estevan.

Os que furun presentes: Pedro Peláez, clérico, Pedro [...]eyfa, Pedro piliteyro, Rodrigo Pérez, monges, Fernán Arias, monges, dun Pedro Garin, o prior dun Garsía Fernan e ouctros muitos queo viron eu oyron.

Notuit Juhan Pérez capellán, públicu notario.

Payu, testis et confirmat; Juhane, testis et confirmat; Sueyro, testis et confirmat.

Pedro, testis; Martín, testis; Rodrigu, testis.

1269, noviembre, 13

El abad Romeu y el convento del monasterio de Vilanova de Lorenzana entregan vitaliciamente a don Fernán Pérez de San Julián y a su mujer doña Sancha Rodríguez, una servicialía en Meirengos exceptuando lo que esté ya contratado, por una renta anual de 15 sueldos pagaderos por San Martín, y con condición de que construyan una casa de piedra cubierta de paja y un hórreo y una cuadra en el plazo de un año desde el día de San Juan y de que la equipen con dos bueyes, dos vacas, quince ovejas y una puerca, todo lo cual quedará libre al monasterio a su muerte. Les entregan también por 13 sueldos de renta la mitad de la servicialía de Saa. El matrimonio se declara familiar del monasterio y ofrece sus cuerpos a sepultura.

A.- AHN, Clero, Lorenzana, carp. 1107, doc. núm. 20. Carta partida por ABC. Pergamino, 11,5 x $7,5 \mathrm{~cm}$. Ligeras raspaduras afectando a alguna letra.

Reg: Índice de documentos..., fol. $10 \mathrm{r}^{\circ}$. 


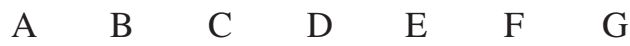

Cunuzuda cousa seia a quantos esta carta virin que eu dun Rumeu, abbade de Villa nova de Laurenzáa, conno conventu desse mismo lugar, damos a dun Fernán Pérez de Sam Iuliau de Revoredo e a sua muller donna Sancha Rodríguiz, una nosa sirvizaya que nos avemus en Meyrengus, salvo u que he encartado e se elles poderem levar do que he encartado per dereytu aimano para esta sirvizaya, e dámusla per tal preytu que elles que nos dem ende cada anno XV solidos aa festa de Sam Martín e que fazan y una casa de parede e cuberta de palla e uno orro e una corte ata este Sam Juhane que ven a un ano e pubrar a casa de dous boys e de duas vacas e de XV roxelos e una porca, ea sua morte dambos fique así pubuada au moesteyro e dámusles mea duna servizaya que nos habemus en Saa e deven nos a dar dela cada ano XIII sólidos aa festa de Sam Martín e teela em sua vida e a sua passagem dambos ficar au moesteyro de susu dicto cum esta ouctra de susu dita livri e quita. Et eu Fernán Pérez de susu dicto oucturgo estes vervos de susu dictos e istes preytus acomprirlos por quanto aio e aver devo en Villa mar e in Cedofeyta ea outorgume por familiaro do moesteyro de susu dicto e mando y meu corpo a mina pasagem e eu dona Sancha ia dicta ${ }^{19}$ ouctorgume por familiara do moesteyro e mando y meu corpo a mina pasagem. E se dun Fernán Pérez demandar do que he encartado per dereytu da sirvizaya de Meyrengus deveo a demandar sem custa do moesteyro, salvo procurazón sele mester for.

Feyta esta carta in Era de mil e CCC e VII anos en cunto, XIII días andados de novembro.

Se dalguén contra este nosso feytu vier así nos como ouctros seia maldictu e peiurado e duble quanto demandar ea voz do rey peyte D sólidos e [a] carta permaezca en sua fortuleza.

Os que furun presentes Juhan Rodríguiz dicto Can, cavaleyro, Diegu Vello, cavaleyro, Salvador Pérez, Juhan Domínguiz da Cazoriga, e Juhan Marino escudeyro e Pedro Iuhanes de Condominna monges defendeu esta carta.

Notario Juhan Pérez público notario de Villa Nova.

Payu, testis et confirmat; Juhane, testis et confirmat; Sueyro, testis et confirmat.

(S.)

Pedro, testis; Martín, testis; Rodrigu testis.

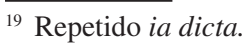


1274, noviembre, 14

El abad Romeu y el convento del monasterio de Vilanova de Lorenzana aforan a seis pobladores y a su descendencia el lugar de Villamariz, exceptuando una plaza ya ocupada, que habitarán y cultivarán como vasallos del monasterio por un canon anual de tres sueldos, sendas fanegas de cebada, sendas gallinas y cuatro celemines de trigo, pagadero mitad por San Martín mitad por Pascua, eximiéndolos del pago de nuncio, gayosa, maniadigo y de la mitad de la cuantía de las penas por hurto, rauso, homicidio y alevosía, acotando el lugar a la injerencia de merino o sayón y estableciendo la elección de alcaldes de mutuo acuerdo.

A.- AHN, Clero, Villanueva de Oscos, carp. 1626, doc. núm. 8. Pergamino, 14 x 24 cm. Margen derecho deteriorado y grandes manchas de humedad impiden la lectura en algunos pasajes.

Reg: Índice de documentos..., fol. $11 \mathrm{r}^{\circ}$.

Cit.: José Villamil y Castro, Los foros de Galicia..., pág. 46. Pegerto SaAvedra, Economía, política y sociedad..., pág. 24.

In nume de Dios amen. Cognuszuda cousa seia a quantos esta carta viren como eu dun Rumeu, abbade do moesteyro de Villa Nova de Laurenzana, aiuntadamente cuno convento desse mismo lugar, damos aquel noso monte cun sua herdade que chaman Villamariz ad seys pobladores, convén a saber quáes: ad Estevao Gunzález et ad Pedro Estévanez una plaza, et a Miguel Pérez et ad Pedro Martín et ad Juhan Iuhannes et ad Fernán Martín et ad Juhan Páez as ouctras cinquo plazas, en tal maneyra que seiades vasalos obidientes a nos e aqueles que en noso lugar vieren et non tomen nunca outro sennor senon o abbade e os frades do moesteyro de susudito et detis a nos cada anno e a os que en noso lugar vieren por foro cada un $\operatorname{tres}^{20}$ soldos de Lion ou a valía deles et sennas fanegas de cevada et sennas galinas et quatro ${ }^{21}$ cilimiis de trigu. E os das [...sen] nos soldos da mueda iadita e sennas meas fanegas de cevada. Et iste foro iadito dévese a pagar a meatade a San Martín e a ouctra meatade a Pasqua, et per este foro seades quitos doutro foro et de rouso et domizio et de furto et daleyvosía, estas quatro vozes a meatade aia u moesteyro iadito ea outra meatade permaesca nos pobladores. E aqueles que y poblaren non den nuzo nen manninadigu nen gayosa nen entre subrelos mayordomo nen sayón et mándense per alcaydes que

\footnotetext{
${ }^{20}$ Repite tres

21 Repite quatro
} 
se ponnan cada ano pelo abbade do ias dito moesteyro et pelos pobladores desse lugar de Villa Mariz. Damus a estes de susuditos este nomeado monte de Villamariz aunadamente cuntagioso per sos términos et per suas antiguas et per sos lugares, que o haian et pussuyan eles et sos filios et suas nueras e sua gearazón que deles sayr per secula cunta, fazendo este foro de susu dito et possan dar et vender aqueles que y pobraren a quen quer que faza este foro de susu dicto. Et sacamos aquel casal cun sua sacada en que moróu Migael Pérez que demus a él et sua voz para iur derdade sen ouctros pobladores. E aqueles que vigaren este casal et ista sacada iadicta deven a seer vasalos do moesteyro susu dito. E así puemos entre nos as partes per secula cunta que se y ouctro for cun ouctras cartas ha que nuncas seian valiosas et ista presente carta que he feyta de nova seia sempre valiosa a todo tempo.

Feyta esta carta in Era de Mil et trezentos e doze anos, e o cunto XIIII días andados de Novembre. Reynando Rey en León et en Castela dun Alfonso. Ricome de Galiza dun Afonso. Bispo de Mondonedo dun Monino. Abbade de Villa Nova dun Rumeu de susu dito.

Si alguén contra este noso feyto vier seia maldictu et periurado et duble quanto demandar ea voz del Rey peyte quinaentos soldos e a carta permaesca en sua furtuleza.

Os que furun presentes, convén a saber quénes: Martín Pérez, monges, dun García Fernández, monges, Iuhan Iohanes d’Orra, Iohan Fernández dito [...] teyro, Pasqual Iohanes, Fernán Míguez, dito Pachela, Pasqual Pérez do Castro, Pedro Gunzálvez, dito Rey. Et eu Juhan Pérez, público notario de Villa nova de Laurenzana, presente fuy et per mandado das partes de susu ditas escriví esta carta e illa pugi meu sinal.

( $1^{a}$ columna) Payu, Juhan, Sueyro, ts. et cfrs. (S.)

( $2^{a}$ columna) Pedro, Martín, Roderico, ts.

1289, mayo, 26

El abad Fernán Pérez y el convento del monasterio de Vilanova de Lorenzana aforan a quince hombres el monte de San Pedro de Munfrugil, que se divide en dieciseis plazas, para que lo pueblen como vasallos obedientes. Cada plaza pagará de foro anual, mitad por San Martín mitad por Pascua, tres sueldos, media tega de trigo o de escanda, media tega de cebada y una gallina. Son exentos de toda multa excepto las de hurto, rauso, homicidio y alevosía, que repartirán a 
medias con el monasterio, y no pagarán nuncio. Elegirán alcaldes propios y podrán acoger en sus plazas pagando un canon.

A.- AHN, Clero, Lorenzana, carp. 1108, doc. núm. 10. Pergamino, 18 x 17,5 cm. Carta partida por ABC. B.- Copia del siglo XIX con transcripción defectuosa, RAH, leg. 9-30-6-6448, núm. 52.

Edita: Javier Alvarado Planas, "Fueros y cartas pueblas inéditas de Galicia", Anuario de Historia del Derecho, 67 (1997), págs. 151-2.

Reg.: Indice de documentos... fol. 100r ${ }^{\circ}$.

Cit.: José Villamil y Castro, Los foros de Galicia..., pág. 47. Pegerto Saavedra, Economía, política y sociedad..., pág. 24.

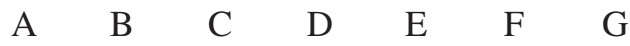

Era de mille e CCCtos e XXVIIe annos, XXVI días de mayo. Connoçuda cousa seia a quantos esta carta viren cómmo eu frey Fernán Pérez, abbade do monesteyro de Villa nova de Lourenzanam e o convento desse mismo lugar damos a pobrar o monte de Sam Pedro de Munfrugil a quinze homnes, convén a saber Matheu Pérez, Martín Peláez, García Fernández, Fernán Iohannis, Johan Miguélez, Pedro Fernández, Pay Fernández, Martín Fernández, Pedro Fernández, Pedro Peláez Ia plaça meas de duas e debe pagar foro e fumadiga, Diego Pérez, Diego Vermúnez, Miguel Martín duas plaças e mea e debe dar pobradores para ellas, Elvira Martín mea plaça e pagar foro e fumadiga e que seian XV plaças e hunna da yglesia e fázense dez e seyx. Et devedes estes pobradores pobrar e morar e seerdes vasallos bonos e leales e obidientes e serventes do moesteyro ia dito e devedes a dar por foro cadaun cada anno a esse mismo moesteyro tres sólidos da moneda de León e mea taega arrapadas de boon trigo ou descanla pisada de cada plaça, pela taega que avedes con nosco ferrada que se faz mea fanega arrapadas, e huna mea taega de bona çeveyra ou de boon orio arrapadas per essa misma taega cada plaça e sennas galinas de cada plaça, et pagar ameade deste foro en día de Sam Martino ea meade en día de Pasqua. E este foro fazendo seeren quitos e livres de todas outras vozes salvo de rouso e da leyvosía e de furto e domezio, et se acaesçeren en este lugar estas vozes, a meatade delas aian os pobradores ea meatade o moesteyro ia dito e non dían nuço ${ }^{22}$.

Et se alguén destes pobradores quisser consigo meter fillo ou filla ou outro homne algún na sua praça en qual maneyra quer día mays hun sólido por foro ao moesteyro ia dito desta moneda sobredito e seia quito commo os outros pobradores. Et esta pobrança mándesse por alcaydes quese ponan cada anno a prazer do abbade e do conçello e que os presente o conçello en outro día de Sancti

\footnotetext{
${ }^{22}$ Sic por nunço.
} 
Espíritus. Et estes pobradores non deven nunca achamar por outro sennorío se non polo do monesteyro ia dito nen criar y fillo nen filla de fidalgo nen doutro nengum sen mandado do monesteyro ia dito. Et seo algún fezer perder a herdade e ficar ao moesteyro livre e quita.

Damos vos este monte e esta herdade per taes téminos, convén a saber: pelo carvallo de Linneyras e pela Fonte do Teixo e pelas Mestas do rego de Mourón e pelo Rego da açoreyra e pela penna da Jusvella e pela Lama do açeveyro e pelo gallo de Fornellus e pela Granda da auturella e pelo Pao do Azevreyro e pelo Marco da pandela, e pelo carballo de Linneyras hu començamos, quanto nos y avemos e aver devemos.

Esta carta seia valiosa a toto tenpo. Et estas vozes e estes foros devennos atirar os alcaydes bien e fielmente commo sobredito he. Et seo assí non feçeren perçan a herdade e fique ao moesteyro ia dito quita e livre. Et pagando este foro compridamente según commose escrito en esta carta deven a aver este monte per sous términos ia ditos commo dito he elles e sua generaçón por jur herdeyro por senpre. Et renuçamos las partes todas las outras cartas e foros seos y ouvo atoesaquí, e valla esta carta por sempre. Et seo alguén alegar ou mostrar non valla. Et estos pobradores se contra estas cousas foren perçan a herdades e fique livre e quita ao moesteyro ia dito.

Et que seia çerto por senpre nos as partes sobreditas rogamos a Juhan Pérez público notario de Villa Nova de Lourenzanam que mandase fazer entre nos esta carta partida per a.b.c e pusesse en ella seu signno.

Testemoyas que estavan presentes: Pedro Peláez, clérigo d’Espasande, Fernán Fernández de Moos, Pedro Eannes de Insoa, clérigo, Pedro Amigo de Ferreyra, Martín Pérez e Nicholao García, monges.

Yo Pedro Cuba estas cartas escriví per mandado do notario ia ito e eu Juhan Pérez notario subredito esta carta mandey escribir a rogo das partes subreditas e eella subescriví e pugi meu sinal acustumado em testemoyo de verdade. (S.)

\section{2}

1400, septiembre, 1.- Monasterio de Vilanova de Lorenzana.

El abad don Lope Arias y el convento del monasterio de Vilanova de Lorenzana, aforan a perpetuidad a Ruy Conde, notario de Villamayor, y a Ruy Sánchez, a medias, el lugar de Montouto de Cadavedo, que está yermo, despoblado y a monte bravo, con todos sus derechos exceptuando el diezmo parroquial, para que en un plazo de cuatro años construyan tres casas de labradores e ins- 
talen tres pobladores que sean vasallos del monasterio. Los foreros pagarán una renta anual de doce libras a veinte sueldos cada libra por la fiesta de San Juan bautista, seis por foro y seis por colecta; y cada labrador pagará al comendero del monasterio exclusivamente un maravedi por comenda y ninguna otra cosa, y el abad habrá de ampararlos como vasallos. Quienes moren en el lugar serán exentos de luctuosa, del subsidio del papa y de cualquier otro pedido del papado. El monasterio tendrá derecho de tanteo.

A.- AHN, Clero, Lorenzana, carp. 1113, doc. núm. 16. Pergamino, 18,5 x $16 \mathrm{~cm}$. Carta partida por $\mathrm{ABC}$.

Reg.: Indice de documentos..., fol. $72 \mathrm{r}^{\circ}$.

Cit.: José Villamil y Castro, Los foros de Galicia..., pág. 48.

Eno nome de Deus amen. Sabeam quantos esta carta de aforamento viren commo eu don Lopo Aras, abbade do monesteiro de Villanova de Lourençana, con outorgamento de Gómez Eanes prior do dito monesteiro e de Fernán Suárez e Gonzalo García, Aras Fernández e Johan Fernández, Lope Eanes, monies (sic) do dito monesteiro. Seendo todos em noso cabidoo per campana tanjuda, segundo que o avemos de huso e de custume, por quanto o lugar de Montotuto de Cadavedo que he do dito monesteiro de Villanova de Lourençana, está hermo e está en montes bravos em tal manera que enno dito lugar de Montouto que non mora nen prova nen lavra ninguén e he hermo de todo ponto, por ende eu o dito don abbade, con outorgamento dos sobreditos prior e monies do dito monesteiro, entendendo que faço serviço de deus e prol e bom juramento do dito monesteiro e meu e dos outros me $<\mathrm{u}>\mathrm{s}$ subçesores que benerem despois de min ao dito monesteiro, aforo e dou a foro por jur de herdade valedera para sempre, a bos Ruy Conde notario, morador enna çibdade de Billamaior, e a todas vosas vozes enna meatade entregamente; et a vos Ruy Sánchis Destoa e a todas vosas vozes enna outra meatade entregamente, convén a saber que vos aforo para senpre segundo dito he, a anbos de permeo e a todas vosas vozes todo o dito logar entregamiente de Montouto de Cadavedo con todas suas herdades e montes e chantados e por chantar e jures e pertinenças e entradas e saydas e pastos e pastos de montes a fontes per hu quier que biram que pertenesçe e pertenesçer deven en qual quier manera a todo o dito lugar e sennorío de Montouto de Cadavedo que pertenesçe e he do dito monesterio de Villanova de Lourençana tirando ende a dezemaria da iglesia do dito lugar de Montouto que non bay en este dito aforamento. Et nos os ditos Ruy Conde e Ruy Sánchez, avedes de fazer tres casas de lavradores enno dito lugar de Montouto e tenerdes enno dito lugar de Montouto tres homnes lavradores que moren e lavren e proven enno dito lugar e han de ser vasallos e obedientes meus e do dito monesteiro e dos outros me $<\mathrm{u}>\mathrm{s}$ suçesores que benerem 
depoys de min ao dito monesteiro. Et avedes de provar o dito lugar de Montouto dos ditos tres homnes lavradores doie este día e era desta carta ata quatro annos contados primeros siguientes.

Et vos os ditos Ruy Conde e Ruy Sánchez e todas vosas vozes acedes de dar e pagar em cada hun anno para senpre a min e aos outros me $<0>$ s suçesores que beneren depois de mín por foro do dito lugar de Montouto doze libras a bynte sólidos por cada huna libra da moneda corrente quese husar a $\mathrm{X}$ dineros por moravedí en esta manera: as seys libras por foro e as outras seis libras por colleita, que se monta asy por todo as ditas doze libras por foro e por colleita. Et avedes de pagar estas ditas doze libras en cada hun anno por cada día de San Iohan Bautista. Et demais cada lavrador que morar e provar enno dito lugar que pague en cada hun anno ao comendero do dito monesteiro hun moravedí por comenda. Et que non seia teudo cada hun lavrador de mays dar nen pagar por comenda nen por outra razón ninhuna ao dito comendero. Et eu o dito abbade e me $<\mathrm{u}>\mathrm{s}$ suçesores que benerem depois de min abemos a defender todos los moradores do dito lugar de Montouto asy commo defendermos os outros homnes e vasallos do dito monesteiro. Et outrosy todos los moradores e provadores que morarem e provarem e lavrarem enno dito lugar e sennorío de Montouto han de ser livres e desesos e exsentos para sempre que non dem nen paguen loytosa nen loytosas ninhunas nen susidio do papa nen outro sou pedido nenhun do papado.

Et nos os ditos Ruy Conde e Ruy Sánchez em nome de nos e de todas nosas vozes asy reçebimos o dito foro de todo o dito lugar e sennorío de Montouto e per las condiçones e maneras sobre ditas, et outorgamos deo tenermos e pagarmos e comprirmos e abregarmos en todo segundo de suso dito he. Et non ocupando e pagando e abregando segundo dito he que o dito lugar que fique livre e desembargado de vos e de todas nosas vozes para sempre ao dito monesteiro con todo o bom paramento que em él estever feito. Et demays querendo nos vender ou subpinnorar o dito lugar que frontemos con él primeramente ao abbade e convento do dito monesteiro, et querendoo por la quantía e preço que outro der que o aiam ante que outro ninhún, et non o querendo que o vendamos a tal persoa ou personas que seiam nosos sevitanes e que cumplam e paguem o dito foro segundo de suso dito he.

Et eu o dito abbade con outorgamento dos sobre ditos prior e monies do dito monesteiro asy vos lo dou e aforo para senpre segundo dito he. Et por que esto seia creudo mando vos dello dar duas cartas feitas em hun tennor ou mays se vos comprirem per lo notario e testimonias subscriptas.

Que fuy feita enno dito monesteiro o primeiro día do mes de setembro, anno da naçença de Ihesu cristo de mille e quatroçentos annos. Et demays por mayor firmidume nos os ditos abbade e prior escrivimos aquí nossos nomes. 
Testimonias que foron presentes ao dito aforamento para ello chamadas e espeçialmente rogadas: Pedro Aras, Ruy López, notarios, moradores en Villanova de Lourençaa. Fernán Eanes morador em Sande e Afonso Eanes morador em Formariz, friglisía de Lagoa e outros.

1447, junio, 30

El abad don Pedro y el convento del monasterio de Vilanova de Lorenzana aforan a perpetuidad a Fernán Pernas y a su mujer Teresa Afonso, y a sus hijos, sus propiedades en Vicos, Mures, Braña y los muradales de San Cosme, que delimitan, por un foro anual de doce maravedís pagaderos el día de San Martín y una colecta al abad de dos libras a veinte sueldos. Cobrarán cuatro maravedís de dos plazas de Braña aforadas y la parte correspondiente de la colecta del abad. Las penas de homicidio, rapto, alevosía y hurto se compartirán a medias con el monasterio, y no serán visitados por mayordomo ni sayón.

A.- AHN, Clero, Lorenzana, carp. 1117, doc. núm. 15. Pergamino, 19,5 x $12 \mathrm{~cm}$. La tinta diluida en algunos puntos impide la lectura.

Reg: Índice de documentos..., fol. 87.

Saban quantos esta carta de foro byren cómmo nos don Pedro, abbade do monesteiro de Bylla Noba de Lourençáa e Gómez Yanes prior e frey Ares e frey Gonzalo, monjes do dito monesteiro, estando todos juntos en noso cabydo según que abemos de uso e de custume entendendo que fazemos nosa prol e bon paramento noso e do dito noso monesteiro, aforamos e damos a foro jur e erdade [...] a vos Fernán Pernas, morador en Vycos, sennorío do dito monesteiro e a vosa muller Taresa Afonso e a todos vosos hijos segú dito he, convén a saber que vos aforamos todos as nosas praças de Vycos e de Mures e de Brana con seus términos e os muradanes de San Cósmede como se departen per la antigoa de San Cósmede e ben topar ao porto da Abra e commo vay a ynfesto e vay topar as agoas santas e dende arriba de Mures commo vay agoa de Laitente e asy caye ao camino de Meanbra e per la penna pequena per la qual se departe o foro de Galgao e tornase ao caminno de Gasallas e dende as Golpeveyras e per meatade do fondo de Branna e entra agoa da Abria e dende arriba ao porto de Lousada segundo se contén enno foro antigo, per tal condiçón que abedes de dar de foro en cada hun anno por cada día de San Martino de nobienbre ao conbento do dito monesteiro doze maravedís de moneda vella ou moneda que tanto valla e abedes 


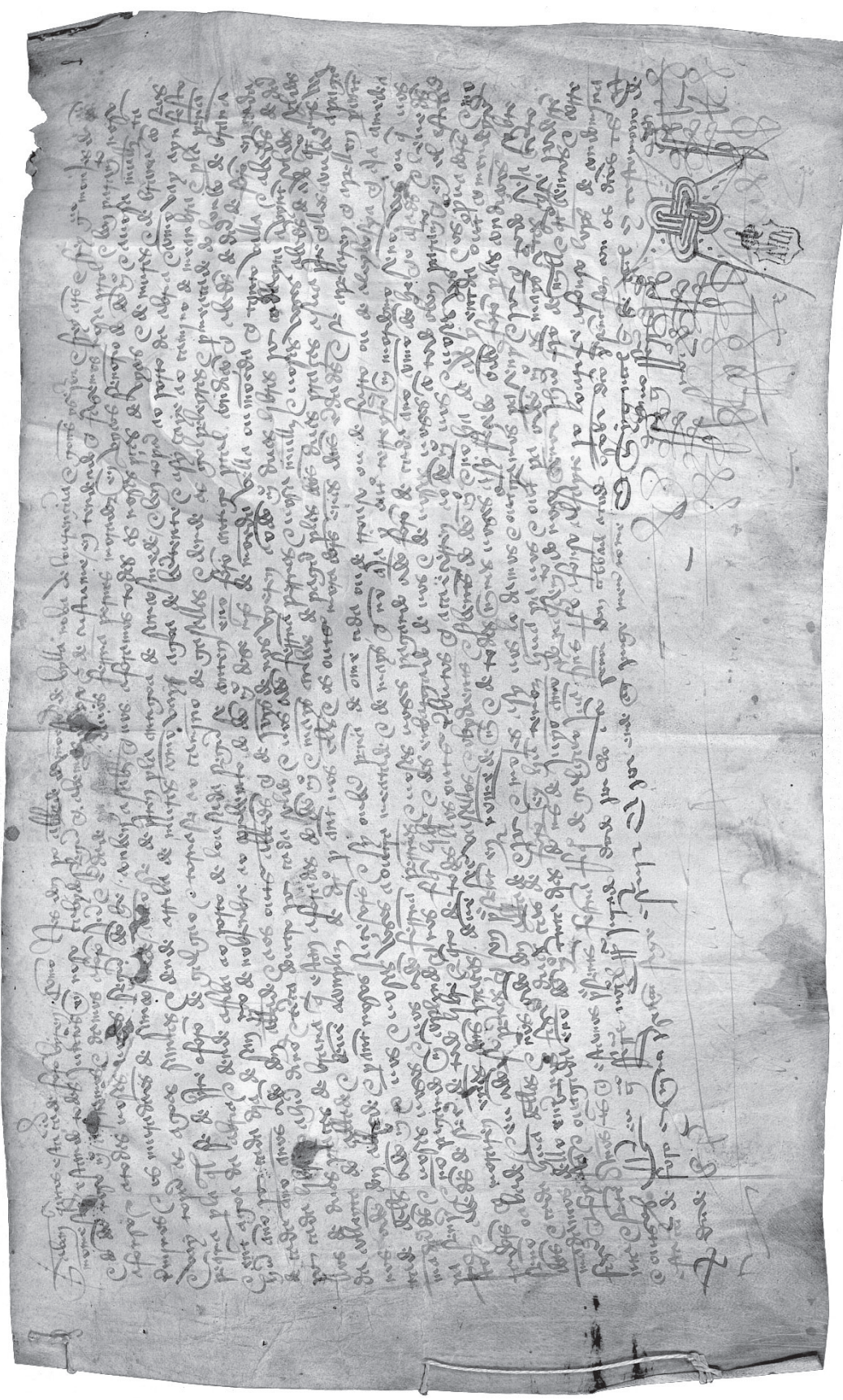

13

AHN, Clero, Carpeta 1117, núm.15r 
de dar de cada anno a nos o dito don abbade e aos outros abbades que depoys de nos vyeren ao dito monesteiro duas libras por colleyta a vynte soldos ${ }^{23}$ por cada libra e a hun dinero e terça doutro por cada sólido. E vos o dito Fernán Pernas e vosa muller e vosas vozes abedes de aver quatro maravedís vellos de duas praças de Brana que están aforadas do dito monesteiro e mays anbos de pagar por las ditas duas praças a sua parte que llos an bir a pagar da colleyta do abbade e deven a cumplir de dereto per ante nos elos e os outros moradores ennas ditas erdades, e se apelaren que apelen perante nos o dito don abbade e per ante nosos suçesores e sy ouber penna de omeçida ou de rouso ou de furto ou de aleybosya, que aja a medeatade delos o dito monesteiro e vos e vosas vozes a outra meatade e de mays que non aja y outro terreytor nin mordomo senon vos ou quen vos mandardes e vosas vozes e vos o dito Fernán Pernas e vosas vozes, pagando o dito foro de cada anno commo dito he que o aiades e levedes para senpre e non pagando nin complindo que nos fique libre e desenbargado de vos e de vosas vozes con todo o bon paramento que en él esteber, ${ }^{24}$ e abedes de ser de todo libre e quito de todos los outros tributos que acaeçeren ao dito monesteiro vos e vosas vozes e os provadores e moradores que moraren ennas ditas praças deven seer vasallos e obydentes e serbentes do dito monesteiro e non ha de aver y entrada outro comendeyro senon o abade.

E eu o dito Fernán Pernas que son presente en nome de mín e de todas minas vozes, asy reçebo o dito foro per las condiçones sobreditas e cada huna dellas; e nos o dito don abbade e prior e monjes asy vos lo damos e outorgamos para sempre; e por que todo seja çerto mandamos dello entre nos fazer duas cartas de foro en hun tenor, huna para vos e outra para o dito monesteiro, as mays çertas que se poderen fazer.

Que foy feita e outorgada enno dito monesteiro, trinta días do mes de junyo, anno do nasçemento do noso sennor Ihesu Cristo de mille quatroçentos e corenta e sete annos.

Testemonias que estamos presentes Fernán Rico de Galgao, Juan Fernández, Ro Afonso alfaytero; Pedro Lourixe, Afonso López de Condominna, e outros.

Eu Gonzalvo Fernández notario póblico jurado dado por el dicho sennor don abbad, a todo o sobredicho presente fuy con os ditos testigos e esta carta de foro en mina presençia fize escribir e por ende aquí puge meu nome e signal que he tal en testemono de verdade.

Gonzalvo Fernández (R.) (S)

\footnotetext{
${ }^{23}$ Repetido soldos.

${ }^{24}$ Repetido stever.
} 
CARTAS DE FUERO Y LICENCIAS AD POPULANDUM DEL MONASTERIO DE

\section{4}

1457, enero, 21.- Monasterio de Vilanova de Lorenzana, capilla del Conde Santo.

El abad don Pedro y el convento del monasterio de Vilanova de Lorenzana aforan a perpetuidad las diez plazas del lugar de Caende por una renta anual pagadera la mitad por San Martín y la mitad por Pascua de cuatro maravedís por plaza al monasterio más un maravedí al comendero. Habrán de habitar, poblar y labrar las heredades o dar quien lo haga, y designarán dos candidatos cada año de los que el abad elegirá un alcalde. El abad se reserva la mitad de las penas de cuchilladas, hurto, rapto y avantadizo.

A.- AHN, Clero, Lorenzana, carp. 1118, doc. núm. 10. Pergamino, 18,5 x $11 \mathrm{~cm}$. El deterioro de la mitad izquierda con la tinta desvaída y dos manchas circulares simétricas impiden la lectura en buena parte del documento.

Reg: Índice de documentos..., fol. 120r .

Edita: José Villamil y Castro, Los foros de Galicia..., pág. 145.

Sepan quantos esta carta de aforamento viren commo nos don Pedro de Cedofeita, abade do monesteiro de San Salvador de Vilanova de Lourençáa, e frey Ares prior, e frey Fernando de Valinno e frey Afonso de Obona e frey Gonzalo, monjes do dito monesteiro, estando juntados per campana tangida enna capela do conde Santo don Osorio que he dentro enno dito monesteiro, aforamos e damos a foro pera sempre jamáis jur de herdade perpetuamente as dez plaças con todas suas herdades bravas e mansas de montes a fontes e pastos e términos e diaçenssos e todas las outras cousas que anos o dito don abade e monjes e convento perteesçen enno noso lugar e aldea de Caende a vos Roy de Cabaneiro e Pedro da Ribeyra e Pedro de Caende e Fernán Castanno e Gomes Pigara e Afonso da Ribeira e García de Sayoane e Rodrigo da Corona, plaçeiros do dito lugar, as ditas dez plaças do dito lugar de Caende e a todas vosas voces e herdeiros e de cada un de vosoutros moradores e povadores enno dito lugar por lo qual foro avedes de dar e pagar en cada un anno aos ditos monjes e convento e prior de cada huna plaça quatro moravedís vellos que fazen tres blancas vellas e un dinero cada un moravedí, a meatade delos por cada día de San Martino de noviembre e a outra meatade por cada día de Pascoa de Resurreyçón, e asy a os outros prior e monjes e convento que despois vieren e foren, e mais ao que for comandeiro da dita abadía un moravedí vello de cada plaça de cada anno, e que vos os ditos plaçeiros avedes morar e provar o dito lugar e labrar as ditas plaças ou dar quen as labre e prove e pague e more e pague os ditos çinco moravedís de cada huna 
plaça. Et mais vos os ditos plaçeiros e vosos sucessores avedes de seer vasalos serventes e obedientes de nos o dito don abade e nosos suçesores e nos servir de cada anno, et os que teen plaças enno dito lugar e moraren de fora dél que dían outros homnes queas labren e moren e proven e paguen e sirvan, et non los dando que venan a nos deyxando e renunçiando e partíndose das ditas plaças e jur e dereto delas para que nos e nosos sucessores las díamos o aforemos a outros a quen quisermos e por ben tevermos, e non las vyndo releixar e partirse delas que nos las pósamos tomar como vacas e dar e aforar a os que nos aplouguer et mais que vos os ditos plaçeiros nos tragades aquí ao dito monesteiro por cada un día de calendas januarias dous cobres en que nos os tomemos e fagamos un alcalde ${ }^{25}$ enno dito lugar de Caende. Et mais que nos o dito don abade e nosos suçessores ave[mos de levar e] aver para nos a meatade de todas las vozes de roussos e furtos e coyteladas e avantadiços do dito lugar de Caende. Et a outra meatade que os aja [e leve] quen for alcalde ende.

Et nos os ditos homnes e plaçeiros por nos e por todos nosos suçessores asy lo outorgamos e obligamos a nos e a nosos heredeiros [...] e por aver de cumplir todo lo sobredito.

Et nos os ditos don abade, prior e monjes e convento así lo outorgamos e mandamos delo [fazer duas cartas que foron] enno tenor susodito que foy feita e outorgada enno dito lugar e capela, día estafeira, vynte e un días do mes de janeyro, anno do naçe[mento do noso Sennor Ieshu] Cristo de mill e quatroçentos e çincoenta e sete annos.

Testigos que foron presentes: Pedro carpenteiro meestro da obra do dito [moesteyro e ...] Fernández moordomo do dito don abade e o prior e monjes. (S.)

Et eu Pedro de Horozco, canónigo da iglesia catedral de Mondonnedo, notario público por la autoridat apostólica a todo esto <que $>$ dito he conos ditos testigos presente fuy e esta carta de foro escriví e aquí en ela puge este meu signo acostumado que tal he en testimonio de verdad, rogado e requirido para elo. (S.)

\section{5}

1463, mayo, 20.- Monasterio de Vilanova de Lorenzana.

El abad Pedro y el convento del monasterio de Vilanova de Lorenzana aforan a perpetuidad a Alfonso Yáñez el “novo” y a su mujer Teresa Fernández y a Juan

\footnotetext{
${ }^{25}$ Repite un alcalde
} 
de Seoane el "novo" y a su mujer Inés Fernández, vecinos del lugar de Braña, en Lorenzana, en la feligresía de Santa María la Mayor, cuanto posee el monasterio en el lugar de Braña, a condición de que vivan allí o den quien lo pueble y paguen anualmente por San Martín de quince curames de pan que no sea trigo. Elegirán un alcalde sobre cuyas apelaciones verá el abad.

A.- AHN, Clero, Lorenzana, carp. 1118, doc. núm. 20. Pergamino, 20 x 13 cm.

Reg.: Indice de documentos..., fol. 119r ${ }^{\circ}$.

Cit. Pegerto SaAvedra, Economía, Política y Sociedad..., pág. 64

Sepan quantos esta carta de aforamento viren commo nos don Pedro abbad do moesteyro de Vila Nova de Lourença entendendo que fazemos nosa prol e bon paramento noso e do dito noso monesteiro e de nosos sucesores que despoes a él de nos vieren aforamos et damos a foro jur hedeiro para sempre a vos Afonso Yannez o nobo, morador en Branna e a vosa muller Teresa Ferrández enna metade e a vos Juan de Seyoane o novo e a vosa Eynes Pérez enna outra meatade, moradores en Lorenzana enno dito lugar de Brana que he su o sino de Santa María Maior, conbén a saber que vos aforamos según dito he todas las nosas herdades de Brana, casas e aguas e herdades bravas e mansas según que perteecen do dito noso monesteiro e montes e pastos e entradas e saydas e agoas con todas suas pertenenças quelles perteecen e pertenecer deven as quaes ditas herdades e casas e casaes e montes e pascos vos a foramos por tal condiçón que moredes e [pr]ovedes enno dito lugar de Brana ou dar quen o more e vosos souçesores que despoys de vos bieren e avedes de dar e pagar a nos o dito don abbade e aos outros abbades que depoys de nos vieren a o dito noso monesteiro quinze curamys de pan medidos per la medida dereyta da çibdad de Vila Mayor do mellor que vos lavredes enas ditas herdades que non seja trigo, e avedes de dar e pagar os ditos quinze curamys de pan enno dito lugar de Brana por cada día de San Martín do mes de novembre e avedes de seer vasalos e obedientes do dito monesteiro e avedes de dar entre vos un alcayde a consyntimento do abbade que for do dito monesteiro e la apelaçión do dito alcayde seja per ante o dito don abbade, e vos os sobreditos Afonso Yanez e Juan de Sayoanne que sodes presentes así receçebides o dito foro per las condiçoes sobreditas e obrigamos a nos e a nosos bees de pagar o dito pan de cada un anno segundo dito he e conprir e abregar as ditas condiçoes segundo dito he e non pagando o dito pan de cada un anno e avregar as ditas condiçoes que nos fiquen as ditas herdades e casas e casaes libres e desembargadas de vos e de vosas vozes con todo o bon paramento 
que en elas esteber. ${ }^{26} \mathrm{E}$ más obrigamos de morar e provar o dito logar segundo dito he nos e nosos suçesores ou releyxar as ditas erdades ao dito monesteiro.

E porque todo esto seja certo e non vena en dulda nos o dito don abbade outorgamos vos delo duas cartas de foro en [un te]nor firmadas de noso nome e firmadas e sygnadas de notario ynfraascrito, unna para vos os sobreditos e outra para nos e para o dito monesteiro, as mays çertas que sobre la dita razón poderen fazer.

Que foy feito e outorgado enno dito noso monesteiro a vinte días do mes de mayo, anno do nascimento de noso sennor Ihesu cristo de mille e quatroçentos e sesenta e tres annos.

Testigos que foron presentes chamados e rogados: frey Gonzalo, monje do dito monesteiro; Alfonso Espelido, Fernando cotes, Lope Alonso, criados do dito sennor abbade e outros.

E eu Gonzalvo Fernández notario público jurado dado por ho sennor abbade, a todo o sobredito presente fuy con os ditos testigos e esta carta de aforamento por mandado do dito sennor abade por outro en mia presença fige escribir e por rogo das ditas partes aquí puge mio nome et signal que he tal en testemoyo de verdad.

(R.) Gonzalvo Fernández, notario. (S.)

\footnotetext{
${ }^{26}$ Repite, abreviado, stever
} 
CARTAS DE FUERO Y LICENCIAS AD POPULANDUM DEL MONASTERIO DE LORENZANA. CONTRIBUCIÓN AL CORPUS DE LOS FUEROS RURALES DE GALICIA

\section{BIBLIOGRAFÍA}

Alvarado Planas, Javier, "Fueros y cartas pueblas inéditas de Galicia", Anuario de Historia del Derecho, 67 (1997), págs. 142-152.

Alvarez Castrillón, José Antonio, Colección diplomática de Santa María de Villanueva de Oscos (1139-1300), Oviedo, RIDEA, 2011.

Barrero García, Ana María y Alonso Martín, María Luz, Textos de derecho local español en la Edad Media. (Catálogo de fueros y costums municipales), Madrid, CSIC, 1989.

Font Rius, José María, Cartas de población y franquicia de Cataluña, vol. I, Madrid, CSIC, 1969.

García Gallo, Alfonso, "Aportación al estudio de los fueros", en Anuario de historia del derecho español, XXVI (1956), págs. 387-446.

Hinojosa, Eduardo de, Documentos para la historia de las instituciones de León y Castilla, Madrid, Centro de Estudios Históricos, 1919.

Mariño Veiras, Dolores, Señorío de Santa María de Meira (s. XII-XVI), A Coruña, Ediciones NOS, 1983.

Martínez Martínez, Faustino, "Antología de textos forales del Antiguo Reino de Galicia (siglos XII-XIV)", Cuadernos de Historia del Derecho, 10 (2003), págs. 257-343.

Muñoz y Romero, Tomás: Colección de fueros y cartas pueblas de España. Catálogo. Madrid, imprenta de D. José María Alonso, 1852.

Pena Domínguez, Ricardo: "Población del Monte de Rúa", Estudios Mindonienses, 11 (1995), págs. 387-400.

Rodríguez Fernández, Justiniano: "Grupo foral de Meira, (Lugo)”, Rev. Archivos Leoneses, 63 (1978), págs. 65-80.

Ruiz de la Peña Solar, Juan Ignacio: "Fueros agrarios asturianos del siglo XIII", Asturiensia Medievalia, 4 (1981), págs. 132-196.

Saavedra, Pegerto: Economía, política y sociedad en Galicia: la provincia de Mondoñedo, 1480-1830, Madrid, Consellería da Presidencia, Xunta de Galicia, 1985.

Sáez Sánchez, Emilio: "Cartas de población del Monasterio de Meira”, Anuario de historia del derecho español, 14 (1943), págs. 500-518.

Villa-Amil y Castro, José: Los foros de Galicia en la Edad Media. Estudio de las transformaciones que ha sufrido en Galicia la contratación, Madrid, Tip. Sucesores de Rivadeneyra, 1884. 